\title{
The HIRLAM fast radiation scheme for mesoscale numerical weather prediction models
}

\author{
Laura Rontu ${ }^{1}$, Emily Gleeson ${ }^{2}$, Petri Räisänen ${ }^{1}$, Kristian Pagh Nielsen ${ }^{3}$, Hannu Savijärvi $^{4}$, and \\ Bent Hansen Sass ${ }^{3}$ \\ ${ }^{1}$ Finnish Meteorological Institute, Helsinki, Finland \\ ${ }^{2}$ Research, Environment and Applications Division, Met Éireann, Dublin, Ireland \\ ${ }^{3}$ Department of Research and Development, Danish Meteorological Institute, Copenhagen, Denmark \\ ${ }^{4}$ Department of Physics, University of Helsinki, 00014 Helsinki, Finland \\ Correspondence to: Laura Rontu (laura.rontu@fmi.fi)
}

Received: 13 January 2017 - Revised: 16 June 2017 - Accepted: 19 June 2017 - Published: 7 July 2017

\begin{abstract}
This paper provides an overview of the HLRADIA shortwave (SW) and longwave (LW) broadband radiation schemes used in the HIRLAM numerical weather prediction (NWP) model and available in the HARMONIE-AROME mesoscale NWP model. The advantage of broadband, over spectral, schemes is that they can be called more frequently within the model, without compromising on computational efficiency. In mesoscale models fast interactions between clouds and radiation and the surface and radiation can be of greater importance than accounting for the spectral details of clear-sky radiation; thus calling the routines more frequently can be of greater benefit than the deterioration due to loss of spectral details. Fast but physically based radiation parametrizations are expected to be valuable for high-resolution ensemble forecasting, because as well as the speed of their execution, they may provide realistic physical perturbations.

Results from single-column diagnostic experiments based on CIRC benchmark cases and an evaluation of 10 years of radiation output from the FMI operational archive of HIRLAM forecasts indicate that HLRADIA performs sufficiently well with respect to the clear-sky downwelling SW and longwave LW fluxes at the surface. In general, HLRADIA tends to overestimate surface fluxes, with the exception of LW fluxes under cold and dry conditions. The most obvious overestimation of the surface SW flux was seen in the cloudy cases in the 10-year comparison; this bias may be related to using a cloud inhomogeneity correction, which was too large. According to the CIRC comparisons, the outgoing LW and SW fluxes at the top of atmosphere are mostly overestimated by HLRADIA and the net LW flux is underestimated above clouds. The absorption of SW radiation by the atmosphere seems to be underestimated and LW absorption seems to be overestimated. Despite these issues, the overall results are satisfying and work on the improvement of HLRADIA for the use in HARMONIE-AROME NWP system is ongoing.

In a HARMONIE-AROME 3-D forecast experiment we have shown that the frequency of the call for the radiation parametrization and choice of the parametrization scheme makes a difference to the surface radiation fluxes and changes the spatial distribution of the vertically integrated cloud cover and precipitation.
\end{abstract}




\section{Introduction}

The radiation parametrizations in a numerical weather prediction (NWP) model serve two purposes. First, they are needed to estimate the radiative heating in the atmosphere due to the vertical divergence of the net longwave (LW, terrestrial) and net shortwave (SW, solar) radiation fluxes. The radiative heating is a source term in the thermodynamics equation in the model and influences the development of atmospheric temperatures and for example the evolution of clouds. Secondly, the radiation parametrizations provide the model with the downward (LWDS, SWDS) and upward (LWUS, SWUS) LW and SW radiation fluxes at the surface, which are part of the surface energy balance and a lower boundary condition for the calculation of atmospheric radiation transfer. NWP models can be validated by comparing forecast surface radiation fluxes to surface observations and forecasts of upward LW and SW fluxes (LWUT and SWUT) at the top of the atmosphere (TOA) to fluxes measured by satellites. Solar radiation (SWDS) forecasts by NWP models are of increasingly greater importance as the role of renewable energy in society grows.

Typically, radiative transfer schemes employed in NWP and climate models are computationally too expensive to be invoked every model time step, or (in some cases) even at every grid column. This potentially compromises the realistic interaction between radiation, cloud and surface processes, and therefore, techniques have been developed for faster radiation calculations to improve the temporal/spatial sampling of the radiation fields (Venema et al., 2007; Manners et al., 2009; Schomburg et al., 2012; Pincus and Stevens, 2013). Rontu et al. (2016b) hypothesized that in mesoscale models, accounting for the fast cloud-aerosol-radiation interactions and a detailed treatment of surface-radiation interactions could be of greater importance than a detailed treatment of clear-sky radiation. For this, the radiation scheme should make optimal use of information about cloud microphysical properties, cloud extent, surface radiation-related properties and aerosol optical properties, that are available in the model. Thus, computationally affordable single spectral interval schemes like HLRADIA (Savijärvi, 1990), documented in this study, and ACRANEB v.2 (Mašek et al., 2016; Geleyn et al., 2017, hereafter denoted as ACRANEB), which can be run at high temporal and spatial resolutions at the expense of high spectral resolution, could be more suitable for mesoscale weather models than schemes developed for the purpose of large-scale, long-range forecasting systems (e.g. the IFS radiation scheme (ECMWF, 2015), denoted hereafter as IFSRADIA).

Future mesoscale numerical weather prediction will increasingly be devoted to very high resolution modelling and rapid updates due to the need for forecasting at short time scales. In view of predictability challenges at high resolution, it is desirable to apply probabilistic methods, ensemble forecasting, even at short ranges. The short-range ensembles must be capable of fast execution. Hence, fast but physically based radiation schemes are desirable. On the other hand, the application of various radiation schemes may provide ensembles with realistic physics perturbations.

A pioneering study by Savijärvi (1990) suggested a fast radiation scheme for mesoscale NWP models in which the radiative transfer was heavily parametrized in order to make the scheme very fast for short-range, limited-area NWP use. This was achieved using one vertical loop for the LW and SW spectral intervals. The scheme, hereafter denoted as HLRADIA, was implemented in the High Resolution Limited Area Model (HIRLAM, Unden et al., 2002) and has been used for operational weather prediction since 1994 (Eerola, 2013), when it replaced the original simple radiation scheme in HIRLAM. Replacing the radiation scheme solved a persistent issue where the surface layer was too cold and humid.

Several improvements have been made to HLRADIA compared to the scheme suggested by Savijärvi (1990). Sass et al. (1994) provided basic documentation on the scheme as implemented in the reference HIRLAM model. They also introduced a scheme for the computation of LW radiative transfer in clouds. Räisänen et al. $(2000 \mathrm{a}, \mathrm{b})$ revised the parametrization of gaseous LW emissivities and stratospheric SW heating due to absorption by $\mathrm{O}_{3}$. Following these revisions, the scheme was implemented in the Rossby Centre regional climate model (RCA, Rummukainen et al., 2001). Wyser et al. (1999) improved the treatment of cloud-radiation interactions by introducing a cloud particle effective radius $\left(r_{\mathrm{e}}\right)$ in the SW and LW parametrizations. Senkova et al. (2007) suggested a parametrization of orographic effects on radiation to account for slope effects over mountainous areas. Minor modifications were also done to HLRADIA to improve LW radiative transfer in the atmospheric boundary layer but these were not documented in scientific literature.

HLRADIA has been recently implemented (Nielsen et al., 2014) in the HARMONIE-AROME NWP model ${ }^{1}$ for test purposes initially. By default, an older version of IFSRADIA (based on cycle 25R, ECMWF, 2015, Sect. 2.2) is applied in this model. Preliminary tests indicate that HLRADIA run at each time-step (every minute) in HARMONIE has the same computational cost as IFSRADIA running at every fifteenth time step (four times in an hour with the 1 min time step used when model's horizontal/vertical resolution is $2.5 \mathrm{~km} / 65 \mathrm{lev}$ els). Within this framework, a new parametrization of aerosol

\footnotetext{
${ }^{1}$ The ALADIN-HIRLAM numerical weather prediction (NWP) system is used for operational weather forecasting by 26 national meteorological services in Europe and North Africa which form the HIRLAM (http://hirlam.org) and ALADIN (http://www. cnrm-game-meteo.fr/aladin/) consortia. The acronym HARMONIE (HIRLAM ALADIN Regional Mesoscale Operational NWP in Europe) denotes the specific configuration of the ALADIN-HIRLAM system maintained by the HIRLAM consortium. The dynamical core and physical parametrizations of HARMONIE-AROME (Bengtsson et al., 2017) are based on AROME, the high-resolution limited area model developed at Meteo-France (Seity et al., 2011).
} 
radiative transfer was incorporated in HLRADIA (Gleeson et al., 2016). The aerosol parametrizations were originally developed for Enviro-HIRLAM, where another version of HLRADIA is applied. Enviro-HIRLAM, the Environment HIgh Resolution Limited Area Model, is a fully online integrated numerical weather prediction and atmospheric chemical transport model (Baklanov et al., 2017). The orographic radiation parametrizations developed for the HIRLAM NWP model have been prepared for use by any atmospheric radiation scheme available in HARMONIE-AROME (Rontu et al., 2016a). The version of HLRADIA available in the HARMONIE-AROME system (i.e. the most up-to-date version of the scheme) is documented in the present study.

Aspects of HLRADIA have been validated in each of the aforementioned studies. Single-column and stand-alone comparisons against detailed radiation transfer calculations and dedicated observations have been performed as well as sensitivity studies and three-dimensional (3-D) modelobservation intercomparisons. Nielsen et al. (2014) pointed out that biases in radiation fluxes predicted by an NWP model can be due to factors other than the atmospheric radiative transfer calculations. Incorrect input to these calculations, such as inaccurate cloudiness, poorly known cloud and surface properties or unaccounted interactions between simulated processes in the model can also lead to errors. To focus on radiative transfer, it is necessary to test against reference radiative transfer models using the same, uniquely defined, input. In the present study, HLRADIA was tested using the single-column framework of Continual Intercomparison of Radiation Codes (CIRC, Oreopoulos et al., 2012).

Validation of radiation output from a 3-D NWP model using radiation observations is useful for understanding the behaviour of the radiation parametrizations in an environment where they interact with all other physical processes in the model. Kangas et al. (2016) compared surface radiation fluxes from the IFSRADIA, ACRANEB and HLRADIA radiation schemes within HARMONIE-AROME to observations at Sodankylä (Northern Finland) for spring 2014. The authors found that HLRADIA tends to overestimate LWDS fluxes when the clouds are optically thick. This evaluation is continued in the present study which includes results from a ten-year comparison between surface radiation observations and FMI operational HIRLAM forecasts for Sodankylä and Jokioinen (Southern Finland), see Fig. 4 for the station locations.

In the present study, we have documented the HLRADIA scheme available in the HARMONIE-AROME system. Such a documentation is necessary for further studies, where the three radiation schemes in HARMONIE-AROME will be systematically compared in 3-D forecast experiments. Such comparisons should allow us to confirm or reject the hypothesis that a more frequent call of the simple radiation schemes is beneficial for mesoscale forecast, because it allows the fast interactions between radiation transfer and clouds and between radiation and the surface to be taken into account.
To partially address this question in the present study, we have included a preliminary example of 3-D HARMONIEAROME experiments for a convective case study over China.

The paper is organised as follows: Sect. 2 summarises the preparation of input variables for the radiative transfer calculations. Section 3 documents the SW and LW HLRADIA atmospheric radiation parametrizations separately for clear and cloudy sky cases and describes how surface-radiation interactions are handled. The results from CIRC comparisons, a ten-year observational evaluation of HLRADIA and a convective case study are detailed in Sect. 4. A summary and outlook are given in Sect. 5.

\section{HLRADIA input variables}

Atmospheric gas composition, aerosol concentration and cloud properties are needed as input at each time-step in every grid cell of the 3-D model for the calculation of radiative transfer. The radiative properties of the surface (i.e. surface temperature, albedo and emissivity) are also required. Information on subgrid-scale variability of surface elevation is used for the calculation of orographic effects on radiation.

The 3-D real-time distribution of water vapour content is available as a prognostic variable in HARMONIE-AROME. The atmospheric constituents ozone $\left(\mathrm{O}_{3}\right)$, oxygen $\left(\mathrm{O}_{2}\right)$ and carbon dioxide $\left(\mathrm{CO}_{2}\right)$ are assumed to be constant in time and space and thus their impact on SW irradiance is also assumed constant. By default, the total column $\mathrm{O}_{3}$ assumed in the SW calculations is fixed at $0.35 \mathrm{~cm}=350 \mathrm{DU}$. The $\mathrm{CO}_{2}$ concentration used in the LW calculations is also represented by a constant value (353 ppmv is used by default in the present operational HIRLAM, while the current measured value is around 400 ppmv. Updating the value would result in an increase in LWDS of ca. $1 \mathrm{~W} \mathrm{~m}^{-2}$ ). The LW and SW absorption by $\mathrm{O}_{2}$ and $\mathrm{O}_{3}$ and the near-infrared absorption by $\mathrm{CO}_{2}$ are accounted for implicitly in the parametrization equations, see Sect. 3.1.1.

The forecast model provides average cloud liquid $\bar{q}_{\text {liq }}$ and ice water $\bar{q}_{\text {ice }}$ content $\left(\mathrm{kg} \mathrm{kg}^{-1}\right)$ for each grid cell for use in the parametrization of radiative transfer in clouds. 3-D diagnostic fractional cloud cover, also available in the model, is then used to derive the in-cloud liquid $\left(q_{\text {liq }}\right)$ and ice water $\left(q_{\text {ice }}\right)$ content from the grid cell averages. The size of the cloud particles is diagnosed using empirical formulas. The effective radius $r_{\mathrm{e}, \text { liq }}$ of the liquid droplets is based on the liquid water content and the assumed-constant number concentration of these droplets in continental and marine clouds (Martin et al., 1994; Wyser et al., 1999). The equivalent radius $r_{\mathrm{e}, \text { ice }}$ of the cloud ice crystals is derived from prognostic temperature and ice water content (Sun and Rikus, 1999; Sun, 2001; Wyser et al., 1999). The shape of the ice crystals is implicitly accounted for when calculating the ice crystal equivalent radius (default shape is hexagonal). Following the example of IFSRADIA (based on the approach of 
Tiedtke, 1996), the in-cloud condensate content $\left(q_{\text {liq }}+q_{\text {ice }}\right)$ in the HIRLAM reference version of HLRADIA is reduced by $20 \%$ after the calculation of the effective particle size, to roughly account for the effects of cloud inhomogeneity. However, in the HARMONIE-AROME version, all clouds are assumed to be homogeneous in both the SW and LW calculations (Nielsen et al., 2014).

In the new parametrization of aerosol radiative transfer available in the HARMONIE-AROME version of HLRADIA, aerosol inherent optical properties (IOPs: optical depth (AOD), single-scattering albedo (SSA) and asymmetry factor $(g)$ ) are estimated based on the GADS/OPAC aerosols in Koepke et al. (1997). The following species are included: soot, mineral dust (nucleation, accumulation, coarse and transported modes), sulphuric acid, sea salt (accumulation and coarse modes), water soluble and water insoluble aerosols. The aerosol types available in HARMONIEAROME and used by the default IFSRADIA, are mapped to GADS/OPAC species in accordance with IFS documention (ECMWF, 2015, chap. 11). For use by HLRADIA, the IOPs are averaged over the entire SW spectrum using prescribed spectral weightings, calculated using the libRadtran/DISORT software package (Mayer and Kylling, 2005; Stamnes et al., 1988, 2000), at a height of $2 \mathrm{~km}$ and a solar zenith angle (SZA) of $45^{\circ}$ for a cloud-free standard midlatitude summer atmosphere (Anderson et al., 1986). The vertical distribution of aerosol species is prescribed using the same exponential profiles as applied in IFSRADIA (also in ECMWF, 2015, chap. 11).

The broadband surface albedo $(\alpha)$ and emissivity $(\epsilon)$ depend on the properties of the underlying surface (e.g. vegetation, desert, water, ice, snow among other types) at each grid point. These are determined using the ECOCLIMAP database (Faroux et al., 2013), surface analysis and surface parametrizations in HARMONIE-AROME. At each timestep LWUS is determined using the grid-average skin temperature and the emissivity (over the different surfaces within the grid cell) derived from the prognostic surface temperature available from the surface parametrizations (SURFEX, Masson et al., 2016). The subgrid-scale variables required for the orographic radiation parametrizations include: slopes and their directions, the local horizon in different directions and a sky view factor as detailed in Senkova et al. (2007) and Rontu et al. (2016a).

\section{Parametrization of radiative transfer}

Downwelling SW and LW radiation fluxes at the surface (SWDS, LWDS) and the profiles of the temperature tendency due to SW and LW irradiances are the primary outputs from the HLRADIA scheme. Net SW and LW fluxes at each model level, including the uppermost level representing the TOA, are derived from the parametrized temperature tendencies (Savijärvi, 1990). Note that this is in contrast to the usual method of parametrizing the fluxes and deriving the heating rates (temperature tendencies) from the net fluxes. Direct and diffuse SW downwelling fluxes at the surface are estimated diagnostically. Cloudy and clear-sky contributions to the SW and LW fluxes are treated separately and the corresponding surface fluxes are available as model output.

\subsection{Single-interval SW radiation scheme}

The temperature tendency due to the absorption of SW radiation is formulated as a sum of absorption in clear and cloudy air. In the following sections, the clear and cloudy parametrizations are described separately.

\subsubsection{Clear-sky transmission}

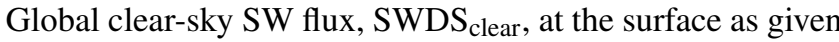
by Eq. (1) is parametrized following the original suggestion by Savijärvi (1990) but the coefficients were retuned as outlined in Gleeson et al. (2015):

$$
\begin{aligned}
\operatorname{SWDS}_{\text {clear }} & =S_{o} \cos \theta\left[1-\frac{0.024+\left(O_{3_{\text {tot }}}-0.35\right) \cdot 0.03}{\sqrt{\cos \theta}}\right. \\
& -0.125 a_{\mathrm{a}}\left(\frac{u}{\cos \theta}\right)^{0.25}-a_{\mathrm{s}} \frac{p_{\mathrm{s}}}{p_{\text {ref }}}\left(\frac{0.28}{1+6.43 \cos \theta}\right. \\
& -0.056 \alpha)],
\end{aligned}
$$

where $S_{o}$ is the TOA solar irradiance which varies from $1321 \mathrm{~W} \mathrm{~m}^{-2}$ (early July) to $1412 \mathrm{~W} \mathrm{~m}^{-2}$ (early January) and $\theta$ is the solar zenith angle. $\mathrm{O}_{3_{\text {tot }}}$ is the total column ozone (in $\mathrm{cm}), u$ is the vertically integrated $\left[0, p_{\mathrm{s}}\right]$ water vapour content $(\mathrm{cm}), p_{\mathrm{s}}$ denotes the surface pressure, $p_{\text {ref }}=1013.15 \mathrm{hPa}$ and $\alpha$ is the surface albedo. The coefficients $a_{\mathrm{a}}(=1.20)$ and $a_{\mathrm{s}}(=1.25)$ were introduced by Savijärvi (1990) to account for aerosol absorption and scattering, respectively, in an approximate manner. The righthandside (RHS) terms of Eq. (1) are related to: (1) the absorption of SW radiation by $\mathrm{O}_{3}$, (2) the absorption of SW radiation by water vapour, $\mathrm{CO}_{2}$ and $\mathrm{O}_{2}$ (i.e. the term proportional to $u$ which is the dominant term in Eq. 1), (3) Rayleigh scattering of the incoming beam and (4) backscattering of reflected radiation from the atmosphere to the surface. The aerosol coefficients $a_{\mathrm{s}}$ and $a_{\mathrm{a}}$ in Eq. (1) are set to unity when the new parametrizations of the direct and semi-direct effects of aerosols are utilised (Gleeson et al., 2016).

The clear-sky SW temperature tendency at each model level is computed from

$$
\begin{aligned}
\frac{\partial T}{\partial t} \mathrm{SW} & =S_{o} \cos \theta \frac{g}{c_{p}} \frac{p}{p_{\mathrm{o}}}\left[Y(u)+1.66 \alpha \cos \theta Y\left(u_{*}\right)\right] \\
& +f_{\mathrm{O}_{3}}+1.7 \times 10^{-6}(\cos \theta)^{0.3}
\end{aligned}
$$

where $g$ is the gravitational acceleration and $c_{p}$ is the specific heat capacity of air at constant pressure. $p$ denotes pressure and $Y$ is an empirical function which depends on the water 
vapour paths experienced by the slant direct $(u)$ and reflected $\left(u_{*}\right)$ beams (Savijärvi, 1990; Sass et al., 1994). The first term represents the parametrized water vapour absorption, $f_{\mathrm{O}_{3}}$ is the absorption of $\mathrm{SW}$ flux by stratospheric $\mathrm{O}_{3}$, parametrized using a prescribed $\mathrm{O}_{3}$ distribution according to Räisänen et al. (2000a), and the last term accounts for the absorption of SW flux by $\mathrm{CO}_{2}, \mathrm{O}_{2}$ and tropospheric $\mathrm{O}_{3}$.

\subsubsection{Cloud transmission}

The SW transmission and absorption are calculated level by level from the cloud top towards the surface. Equation (1), scaled by the pressure at the cloud top (instead of $p_{\mathrm{s}}$ ) and using a parametrized cloud top albedo (instead of the surface albedo), is used to represent the incoming SWD at the top of the uppermost cloud layer. The SW radiation flux transmitted through clouds is calculated using cloud SW absorptivity $(\hat{A})$ and transmissivity ( $\hat{T})$ broadband functions (Eq. 3 ), which are derived from fits to a two-stream five-band radiative transfer model as outlined in Savijärvi et al. (1997) and $\mathrm{Hu}$ and Stamnes (1993). Within and below clouds the clearair values are reduced by the cloud transmittance $\hat{T}$. Within clouds there is also extra heating due to cloud particle absorption, represented by the flux convergence of the absorptivity $\hat{A}$.

The functions $\hat{A}$ and $\hat{T}$ depend on $\theta$, the combined cloud liquid and ice content $\hat{M}[0, p]$ above the level $(p)$ for which $\hat{A}[0, p]$ and $\hat{T}[0, p]$ are calculated, and on the vertically integrated effective radius $\hat{r}_{\mathrm{e}}[0, p]$ of the cloud particles for SW calculations:

$$
\begin{aligned}
& \hat{A}=b_{10}\left(b_{11}+\cos \theta\right) \log \left(1+b_{12} \hat{M}\right) \\
& \hat{T}=\frac{\hat{T}_{1}}{\hat{T}_{1}+\hat{M}}
\end{aligned}
$$

$\hat{M}=\frac{1}{\mathrm{fr}_{\text {cloud,max }}} \int_{p}^{0} \operatorname{fr}_{\text {cloud }}\left(p^{\prime}\right)\left[q_{\text {liq }}\left(p^{\prime}\right)+q_{\text {ice }}\left(p^{\prime}\right)\right] \mathrm{d} p^{\prime}$,

where $\hat{T}_{1}=b_{13}\left(b_{14}+\cos \theta\right), b_{10}=b_{10 a} \hat{r}_{\mathrm{e}}+b_{10 b}$ and $b_{13}=$ $b_{13 a} \hat{r}_{\mathrm{e}}+b_{13 b^{2}}$ and $p^{\prime}$ denotes pressure used in vertical integration. In each column, the fractional cloud cover at a particular model level $\operatorname{fr}_{\text {cloud }}\left(p^{\prime}\right)$ is scaled by the maximum cloud cover above it $\left(\mathrm{fr}_{\text {cloud,max }}\right)$ when calculating the vertically integrated cloud condensate content $\hat{M}$. The vertically integrated effective radius $\hat{r}_{\mathrm{e}}$ is determined by weighting the liquid and ice effective radiuses of each layer by the corresponding cloud fraction and the in-cloud liquid and ice contents above the level under consideration:

$\hat{r}_{\mathrm{e}}=\frac{\int_{p}^{0} \mathrm{fr}_{\text {cloud }}\left(p^{\prime}\right)\left[q_{\text {liq }}\left(p^{\prime}\right) r_{\mathrm{e}, \text { liq }}\left(p^{\prime}\right)+q_{\text {ice }}\left(p^{\prime}\right) r_{\mathrm{e}, \text { ice }}\left(p^{\prime}\right)\right] \mathrm{d} p^{\prime}}{\int_{p}^{0} \operatorname{fr}_{\text {cloud }}\left(p^{\prime}\right)\left[q_{\text {liq }}\left(p^{\prime}\right)+q_{\text {ice }}\left(p^{\prime}\right)\right] \mathrm{d} p^{\prime}}$.

\footnotetext{
${ }^{2}$ Values of the $b$-coefficients are: $b_{10 a}=1.55 \times 10^{-4}, b_{10 b}=$ $8.18 \times 10^{-3}, b_{11}=1.29, b_{12}=0.545, b_{13 a}=7.00, b_{13 b}=-4.75$, $b_{14}=8.30 \times 10^{-2}$.
}

\subsection{Diagnosis of the direct and diffuse SW radiation at the surface}

Direct and diffuse SW fluxes at the surface are diagnosed from the downwelling clear and cloudy sky fluxes. Diffuse SWDS consists of the flux (1) scattered by atmospheric gases and aerosol particles, (2) transmitted through clouds and (3) reflected by the surface and rescattered towards the surface multiple times.

In the HIRLAM reference version of HLRADIA, all SWD transmitted through clouds is considered to be diffuse. Clearsky diffuse radiation $\mathrm{SWDS}_{\text {dif,clear }}$ is approximated by a simple empirical formula based on Paltridge and Platt (1976):

$\operatorname{SWDS}_{\text {dif,clear }}=100\left(1-e^{-2.865 h}\right)$,

where $h=(\pi / 2-\theta)$ is the solar elevation angle in radians. Direct radiation at the surface $\left(\mathrm{SWDS}_{\mathrm{dir}}\right)$ is obtained as a difference between the global clear-sky radiation $\left(\mathrm{SWDS}_{\text {clear }}\right.$, Eq. 1) and the sum of diffuse radiation from the cloudy and clear sky parts.

In the HARMONIE-AROME version of HLRADIA, direct and diffuse radiation are diagnosed both for the clear and cloudy parts of each gridbox, taking into account scattering by air molecules, aerosols and cloud particles. The transmittance of delta-scaled direct solar irradiance though clouds is also accounted for. Further testing of these parametrizations is ongoing and the results will be reported in future publications.

\subsection{Single-interval LW radiation scheme}

In terms of LW radiative transfer each atmospheric layer interacts with all other clear and/or cloudy-sky layers. However, in HLRADIA, these interactions are greatly simplified and include only the following: (1) cooling to space, (2) the interaction between the layer in question and the surface and (3) the interactions between the layer in question with the vertically integrated cloud layers above and below that layer. This means that the energy exchange between clear-air atmospheric layers is neglected and that between clear and cloudy layers is treated in a simplified manner. LWDS below the cloud base is the sum of contributions from the clear sky and cloud-covered parts.

\subsubsection{Clear-sky parametrizations}

The LW clear sky parametrization uses a broadband emissivity scheme where an isothermal approximation is assumed locally. The LW transmission follows that of Räisänen et al. (2000a). ${ }^{3}$ Total water vapour emissivity $\left(\epsilon_{\mathrm{H}_{2} \mathrm{O}}\right)$ is defined as a sum of water vapour line $\left(\epsilon_{\text {line }}\right)$ and continuum $\left(\epsilon_{\text {cont }}\right)$ absorption. The total emissivity of atmospheric gases is obtained by

\footnotetext{
${ }^{3}$ This Helsinki University report is only available as a printed document; relevant parts are attached as a Supplement.
} 
combining $\epsilon_{\mathrm{H}_{2} \mathrm{O}}$ with $\mathrm{CO}_{2}\left(\epsilon_{\mathrm{CO}_{2}}\right)$ absorption,

$\epsilon_{\mathrm{H}_{2} \mathrm{O}}=\epsilon_{\text {line }}+a\left(1-\epsilon_{\text {line }}\right) \epsilon_{\text {cont }}$

$\epsilon_{\mathrm{tot}}=\epsilon_{\mathrm{H}_{2} \mathrm{O}}+b\left(1-\epsilon_{\mathrm{H}_{2} \mathrm{O}}\right) \epsilon_{\mathrm{CO}_{2}}$,

where $a$ and $b$ account for the non-random spectral overlap between the corresponding components. Empirical expressions for the emissivities, which depend on specific gas concentrations, pressure and temperature (effective path lengths) and the functions $a$ and $b$, were derived by Räisänen et al. (2000a), see the Supplement. The equation for clear-sky LWDS is thus given as:

$\mathrm{LWDS}=\int_{p_{\mathrm{s}}}^{0} B\left(T_{p}\right) \mathrm{d} \epsilon_{\mathrm{tot}}\left(p, p_{\mathrm{s}}\right)+c_{\mathrm{sur} 1}$

where $B\left(T_{p}\right)$ is the blackbody radiation at pressure $p$ (with temperature $\left.T_{p}\right) . c_{\text {sur } 1}=8-20 \mathrm{~W} \mathrm{~m}^{-2}$ represents the effect of additional greenhouse gases $\left(\mathrm{O}_{3}, \mathrm{CH}_{4}, \mathrm{~N}_{2} \mathrm{O}\right.$, the CFCs) and aerosols. The value of $c_{\text {sur1 }}$ is enhanced by up to 1.6 times when the lowest model layer is dry $\left(\epsilon_{\mathrm{H}_{2} \mathrm{O}}\right.$ is small). In practice, this term has been used as a tuning factor in order to improve the simulated surface energy balance in HIRLAM.

The temperature tendency $\left(\mathrm{K} \mathrm{s}^{-1}\right)$ due to $\mathrm{LW}$ radiation is given by

$$
\begin{aligned}
\frac{\partial T}{\partial t} \mathrm{LW} & =-B\left(T_{p}\right) \frac{g}{c_{p}} \frac{\partial \epsilon_{\mathrm{tot}}(0, p)}{\partial p} \\
& +\left[B\left(T_{\mathrm{s}}\right)-B\left(T_{p}\right)\right] \frac{g}{c_{p}} \frac{\partial \epsilon_{\mathrm{tot}}\left(p, p_{\mathrm{s}}\right)}{\partial p} \\
& -1.5 \times 10^{-6}(3 \eta-1),
\end{aligned}
$$

where $\eta$ denotes the pressure-based hybrid vertical coordinate used in HIRLAM and HARMONIE ([0,1], $\eta \approx p / p_{\mathrm{s}}$ ). The RHS terms are related to gaseous absorption above the layer in question $[0, p]$ (first term: "cooling to space"), to gaseous absorption between the layer and the surface $\left[p, p_{\mathrm{s}}\right]$ (second term: "heating from the ground") and a correction for other gases and aerosols (third term).

To avoid overestimating the "heating from the ground" in the lowermost layer (layer nlev), the computation of the second term is modified in that layer. Because the ground interacts more efficiently with the lower than upper parts of the lowermost layer, the difference $T_{\mathrm{s}}-T_{p \text {,nlev }}$ is reduced empirically by multiplying it by $2 / 3$. This semi-empirical approximation is based on the assumption of a logarithmic temperature profile in the lowest half-layer with a roughness length of a few centimetres.

\subsubsection{Cloud emission and absorption}

According to Wyser et al. (1999), the cloud effective emissivity (also denoted as the effective cloud cover) for each layer is given as

$\epsilon_{\text {cloud }}=\operatorname{fr}_{\text {cloud }}\left[1-\exp \left(-k_{\mathrm{a}, \text { liq }} M_{\text {liq }}-k_{\mathrm{a}, \text { ice }} M_{\text {ice }}\right)\right]$ where $\mathrm{fr}_{\text {cloud }}([0,1])$ is the fractional cloud cover and $M_{\text {liq }}$ and $M_{\text {ice }}$ are given in units of $\mathrm{g} \mathrm{m}^{-2}$. The cloud mass absorption coefficients $k_{\mathrm{a}, x}$ depend on the effective radius,

$k_{\mathrm{a}, x}=c_{1, x}+c_{2, x} \exp \left(-c_{3, x} r_{\mathrm{e}, x}\right)$,

where the index $x$ refers to cloud liquid droplets or cloud ice crystals ${ }^{4}$.

The computation of the LW heating or cooling rate in a layer is split into four parts (Sass et al., 1994), which contribute to the total temperature tendency. The scheme applies a maximum cloud overlap assumption. There are contributions from: (1) the clear air part of the gridbox over which there are no clouds, (2) the clear air part with clouds overhead, (3) the cloudy part over which there are no clouds and (4) the cloudy part with clouds overhead. The maximum effective cloud cover above and below each layer is determined and used for the calculation of the total cloud emissivity in both the upward and downward directions.

\subsection{Aerosol radiative transfer}

Originally, the aerosol SW effects were treated by the coefficients $a_{\mathrm{a}} a_{\mathrm{s}}$ (Eq. 1) and aerosol LW absorption was included via the (tunable) extra terms in Eqs. (7) and (8), which account for the impact of "the other gases" and aerosols. In the new parametrization of aerosol radiative transfer, available in the HARMONIE-AROME version of HLRADIA, aerosol transmittance, reflectance and absorptance are calculated using the two-stream approximation equations for anisotropic non-conservative scattering described by Thomas et al. (2002). The radiative temperature tendency due to aerosol absorption is calculated at each model level starting from the top. Different parametrizations are applied for the cloudy and clear sky fractions: (1) above the uppermost cloud top (clear), (2) from this to the lowermost cloud bottom (cloudy) and (3) below the clouds (clear). Improvement of the aerosol LW transfer parametrization for HLRADIA is ongoing. Note that in the present study the new aerosol parametrizations were applied only for the case study (Sect. 4.3) because the aerosols were excluded in the singlecolumn comparisons (Sect. 4.1) and the old formulations are used in operational HIRLAM NWP model (Sect. 4.2).

\subsection{Surface-radiation interactions}

Spectral surface albedos for the six SW bands of IFSRADIA are calculated based on data in the UV, visible and nearinfrared intervals provided by SURFEX. For HLRADIA, a basic (diffuse flux) broadband albedo $\left(\alpha_{\text {dif }}\right)$ is determined from these using the same spectral weightings as applied

\footnotetext{
${ }^{4}$ Values of the $c$-coefficients are: $c_{1, \text { liq }}=0.0255, c_{2, \text { liq }}=$ $0.0570, c_{3, \text { liq }}=-0.0890$ and $c_{1, \text { ice }}=0.0202, c_{2, \text { ice }}=0.2059$, $c_{3, \text { ice }}=-0.0672$. See Sect. 2 for the calculation of $r_{\mathrm{e}, \text { liq }}$ and $r_{\mathrm{e} \text {,ice }}$ (unit: $\mu \mathrm{m}$ )
} 
in the aerosol parametrizations (Sect. 2), computed from the spectral distribution of downwelling solar flux at the height of $2 \mathrm{~km}$ for the standard midlatitude summer atmosphere, assuming a SZA of $45^{\circ}$. An empirical correction term which depends on SZA is added to obtain the direct beam albedo $\left(\alpha_{\text {dir }}\right)$ as follows:

$\alpha_{\mathrm{dir}}=\alpha+\frac{0.2}{1+\cos \theta}-0.12$.

A description of the orographic radiation parametrizations is not presented here but can be found in Senkova et al. (2007), Wastl et al. (2015) and Rontu et al. (2016a).

\section{Evaluation}

In this section HLRADIA is evaluated in the CIRC single column framework for a range of benchmark cases (Sect. 4.1) and separately in the HIRLAM 3-D reference model v.7.4, applied operationally at the Finnish Meteorological Institute (Sect. 4.2). A 3-D sensitivity experiment, involving IFSRADIA, HLRADIA and ACRANEB is reported in Sect. 4.3.

\subsection{CIRC}

Continual Intercomparison of Radiation Codes (CIRC, Oreopoulos et al., 2012) benchmark cases were used to evaluate the HLRADIA radiation scheme; a standalone version was built for this purpose. Outputs were compared to those from a line-by-line (LBL) model (LBLRTM for LW and LBLRTM/CHARTS for SW, Clough et al., 2005) except for atmospheric profiles of net SW fluxes and SW heating rates which are unavailable. Results from a narrowband reference used for the development of ACRANEB (Mašek et al., 2016; Geleyn et al., 2017), hereafter referred to as NBM, are also included in the comparisons. In addition to the spectral resolution of the computations, the LBL and NBM references differ mainly with respect to angular resolution: LBL uses 16 streams for SW $(0.2-12.2 \mu \mathrm{m})$ and 6 streams for LW (3$1000 \mu \mathrm{m})$ irradiance computations while NBM uses a deltatwo-stream approximation in the SW $(0.245-4.642 \mu \mathrm{m})$ and LW (4.642-105 $\mu \mathrm{m})$ wavelength ranges.

\subsubsection{CIRC cases}

Nine CIRC Phase 1 subcases were used in the comparisons presented here; these are summarised in Table 1 which provides details on precipitable water vapour (PWV), liquid water path (LWP), the average cloud liquid effective radius $\left(\hat{r_{\mathrm{e}}}\right)$, cloud levels, surface albedo, SZA, $\mathrm{CO}_{2}$ and location. The CIRC Phase 1 benchmark cases were built around observations by the Atmospheric Radiation Measurements programme (ARM, 2016) and represent atmospheric conditions that are not overly complex. The subcases are idealised forms of these benchmark cases. Figure 1 shows the input temperature and humidity profiles for each case. Note that case 2 is particularly warm and humid while cases 4 and 5 represent cold and dry conditions in Alaska.

All but two of the CIRC subcases presented here represent clear sky aerosol-free conditions. The two exceptions are subcases $6 \mathrm{~b}$ and $7 \mathrm{a}$ which involve a thick and a moderately thin liquid cloud respectively; in each case the cloud occupies adjacent model levels covering the depth given in Table 1. The vertical distributions of the specific cloud liquid water content and cloud droplet effective radius were prescribed for these cases. In each cloudy case the fractional cloud cover for the cloud-containing levels was considered to be $100 \%$.

\subsubsection{CIRC results}

For each CIRC subcase we have compared the SWDS, LWDS, LWUT and SWUT fluxes from HLRADIA and NBM to LBL output (Table 2). Net LW radiation flux profiles and LW heating rate profiles were compared to LBL output and are shown for selected cases in Figs. 2 and 3, respectively. For the CIRC cases, net SW radiation fluxes and heating rate profiles from LBL are not available for use as a reference. However, assumptions related to cloud microphysical and optical properties in NBM make it unsuitable for use as a reference for SW comparisons. For these reasons, the comparison of SW fluxes and heating rates in the atmosphere is left for a further study.

The clear-sky SW flux errors for HLRADIA relative to the LBL model are small but systematic (Table 2). SWDS is overestimated by $6-8 \mathrm{~W} \mathrm{~m}^{-2}$ and SWUT by $7-19 \mathrm{~W} \mathrm{~m}^{-2}$ (the SWUT error is largest in the Arctic cases 4 and 5). This indicates that atmospheric SW absorption is systematically underestimated by HLRADIA. Such underestimation is related to Eq. (2), which involves several empirical approximations which may need to be improved. SWDS is also overestimated by NBM relative to LBL but the bias in SWUT is small. In the cloudy cases the absolute value of the SWDS bias is greater than in the clear cases, 10 and $-18 \mathrm{~W} \mathrm{~m}^{-2}$ for HLRADIA, -23 and $20 \mathrm{~W} \mathrm{~m}^{-2}$ for NBM for cases $6 \mathrm{~b}$ and 7 a respectively. For these cases, HLRADIA overestimates SWUT by 18 and $15 \mathrm{~W} \mathrm{~m}^{-2}$ and NBM overestimates it by even more, 37 and $25 \mathrm{~W} \mathrm{~m}^{-2}$. The cloudy case results are sensitive to the way in which the cloud liquid droplet size, represented by $r_{\mathrm{e}}$, is treated (not shown). Such uncertainties of the SW transmission, related to the definitions of cloud optical properties in HLRADIA and NBM, require further study.

In each clear-sky case, the HLRADIA LWDS is within $7 \mathrm{~W} \mathrm{~m}^{-2}$ of the LBL results, but the bias is positive for the warm cases (1b, 2b, 3b and 7b) and negative for the colder cases $(4 \mathrm{~b}, 5 \mathrm{~b}, 6 \mathrm{~b})$. This suggests that the constant $c_{\text {sur } 1}$ (Eq. 7 ) should in fact not be constant but instead larger for cold/dry conditions than for warm/moist conditions. The biases are small and positive for the two cloudy subcases. Here the result was improved because $c_{\text {sur1 }}$ was set to zero below the 
Table 1. CIRC experiments ( $\mathrm{SGP}=$ Southern Great Plains, NSA = Northern Slope of Alaska). Clouds in $6 \mathrm{~b}$ and $7 \mathrm{a}$ consist of liquid water droplets.

\begin{tabular}{|c|c|c|c|c|c|c|c|c|c|}
\hline $\begin{array}{l}\text { Case/ } \\
\text { Atmosph. conditions }\end{array}$ & $1 b$ & $2 b$ & $3 b$ & $4 \mathrm{~b}$ & $5 b$ & $6 b$ & $6 \mathrm{~d}$ & $7 \mathrm{a}$ & $7 b$ \\
\hline Location & SGP & SGP & SGP & NSA & NSA & SGP & SGP & Pt. Reyes & Pt. Reyes \\
\hline $\operatorname{SZA}\left({ }^{\circ}\right)$ & 47.9 & 64.6 & 40.6 & 55.1 & 55.1 & 45.5 & 45.5 & 41.2 & 41.2 \\
\hline $\operatorname{PWV}\left(\mathrm{kg} \mathrm{m}^{-2}\right)$ & 12.3 & 48.5 & 23.1 & 3.2 & 3.2 & 19.0 & 19.0 & 24.2 & 24.2 \\
\hline Clouds & clear & clear & clear & clear & clear & thick & clear & moderately thin & clear \\
\hline Cloud layer (hPa) & - & - & - & - & - & $950-800$ & - & $993-979$ & - \\
\hline $\operatorname{LWP}\left(\mathrm{g} \mathrm{m}^{-2}\right)$ & 0 & 0 & 0 & 0 & 0 & 263.4 & 0 & 39.1 & 0 \\
\hline$\hat{r}_{\mathrm{e}}(\mu \mathrm{m})$ & - & - & - & - & - & 6.8 & - & 8.8 & - \\
\hline Albedo & 0.20 & 0.19 & 0.17 & 0.67 & 0.67 & 0.14 & 0.14 & 0.16 & 0.16 \\
\hline $\mathrm{CO}_{2}(\mathrm{ppmv})$ & 360 & 360 & 360 & 375 & 750 & 360 & 360 & 380 & 380 \\
\hline
\end{tabular}

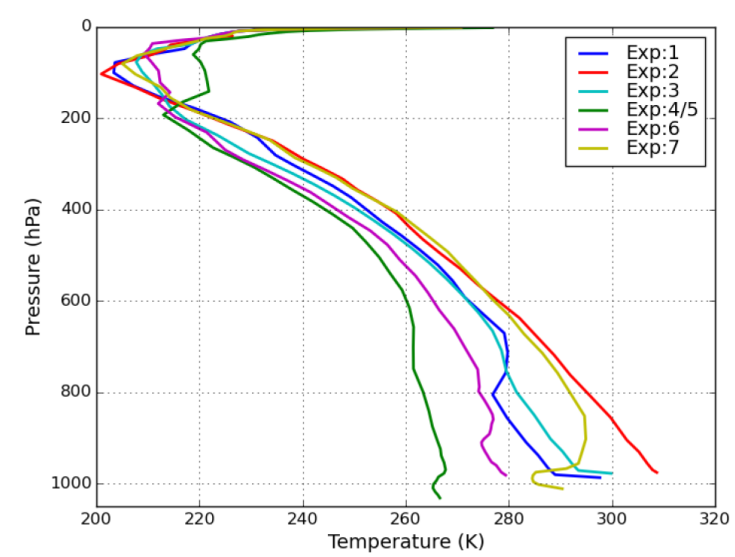

(a)

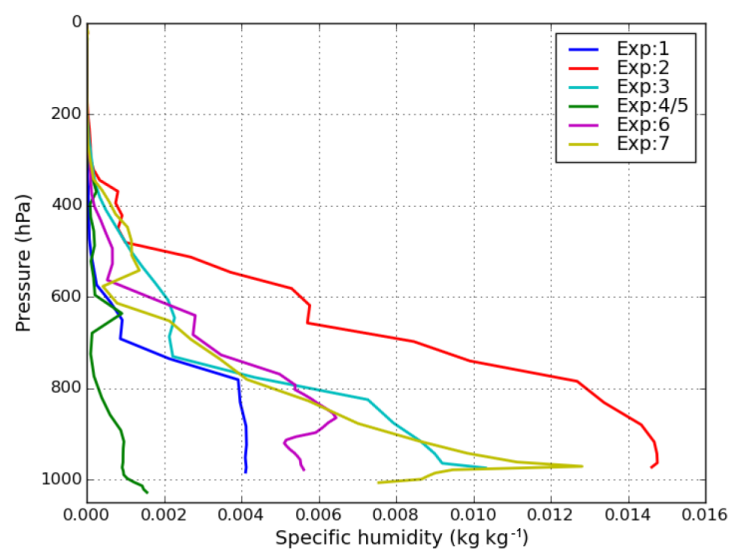

(b)

Figure 1. Input (a) temperature (K) and (b) specific humidity $\left(\mathrm{kg} \mathrm{kg}^{-1}\right)$ profiles for the 7 CIRC cases.

clouds. The biases in LWDS for NBM relative to LBL are small and positive for all cases $\left(<9 \mathrm{~W} \mathrm{~m}^{-2}\right)$.

The biases for LWUT for NBM are small and negative in all cases $\left(>-8 \mathrm{~W} \mathrm{~m}^{-2}\right)$ while the biases for HLRADIA are positive for the clear-sky subcases $\left(4-7 \mathrm{~W} \mathrm{~m}^{-2}\right)$ and larger and negative for the cloudy cases $\left(<-20 \mathrm{~W} \mathrm{~m}^{-2}\right)$. Thus, HLRADIA strongly overestimates the cloud radiative effect (i.e. underestimates the radiative cooling of the cloudy atmosphere to space) compared to the LBL results. This is also indicated by the difference in LWUT between cases $6 \mathrm{~b}$ and $6 \mathrm{~d}, 7 \mathrm{a}$ and $7 \mathrm{~b}$. For HLRADIA these differences are 39 and $33 \mathrm{~W} \mathrm{~m}^{-2}$, respectively, but only $6 \mathrm{Wm}^{-2}$ in each case for LBL and 9 and $7 \mathrm{~W} \mathrm{~m}^{-2}$ for NBM. In terms of the atmospheric LW budget, which is defined as positive when the atmosphere as a whole gains energy, the bias in HLRADIA with respect to LBL is $-11-2 \mathrm{~W} \mathrm{~m}^{-2}$ for the clear cases and $20-24 \mathrm{~W} \mathrm{~m}^{-2}$ for the cloudy cases compared to the LBL results. Thus, according to HLRADIA the atmosphere looses less energy due to the LW cooling than according to the LBL results. For NBM, the corresponding differences are -3 to 1 and -3 to $6 \mathrm{~W} \mathrm{~m}^{-2}$, for the clear and cloudy cases, respectively.

For the clear sky cases, e.g. case $2 b$ (Fig. $2 a$ and b), the net model-level LW fluxes computed by HLRADIA and NBM mostly agree with the LBL fluxes to within $10 \mathrm{~W} \mathrm{~m}^{-2}$. The results for the remaining cases $(1 b, 3 b, 4 b, 5 b, 6 d, 7 b)$ are similar (not shown). For the cloudy cases (6b, Fig. $2 \mathrm{c}$ and d, $7 \mathrm{a}$, Fig. $2 \mathrm{e}$ and $\mathrm{f}$ ), the bias for HLRADIA relative to LBL is large above the cloud, where it is of the order of 20$40 \mathrm{~W} \mathrm{~m}^{-2}$. The bias in NBM relative to LBL is largest at the top of the cloud but then decreases to less than $10 \mathrm{~W} \mathrm{~m}^{-2}$.

The HLRADIA bias in LW heating rate relative to LBL output is mostly less than $1 \mathrm{Kday}^{-1}$ for the clear sky cases (Fig. 3a and b). For the cloudy subcases (Fig. 3c, d, e and f) the HLRADIA LW heating biases increase to mostly 10 $15 \mathrm{~K} \mathrm{day}^{-1}$ near the cloud top but are small otherwise. In the clear case $2 b$, NBM shows a negative bias of $-4 \mathrm{~K} \mathrm{day}^{-1}$ for LW heating close to the surface while for the cloudy cases the underestimation of the cloud-top LW cooling and biases throughout the atmosphere by NBM and HLRADIA vs. LBL are of comparable magnitude. 
Table 2. LBL surface and TOA SW and LW fluxes and the relative difference between HLRADIA and NBM and LBL: HLRADIA minus LBL, NBM minus LBL. Fluxes out from the atmosphere to the ground (SWDS, LWDS) and space (SWUT, LWUT) are denoted positive.

\begin{tabular}{|c|c|c|c|c|c|c|c|c|c|}
\hline Experiment/Model & $1 \mathrm{~b}$ & $2 b$ & $3 b$ & $4 \mathrm{~b}$ & $5 b$ & $6 \mathrm{~b}$ & $6 \mathrm{~d}$ & $7 \mathrm{a}$ & $7 b$ \\
\hline & \multicolumn{9}{|c|}{ SWDS $\left(\mathrm{W} \mathrm{m}^{-2}\right)$} \\
\hline LBL & 720 & 384 & 790 & 645 & 643 & 94 & 745 & 475 & 761 \\
\hline HLRADIA-LBL & 6 & 8 & 7 & 6 & 8 & 10 & 7 & -18 & 7 \\
\hline \multirow[t]{2}{*}{ NBM-LBL } & 6 & 6 & 8 & 8 & 8 & -23 & 7 & 20 & 7 \\
\hline & \multicolumn{9}{|c|}{$\operatorname{LWDS}\left(\mathrm{W} \mathrm{m}^{-2}\right)$} \\
\hline LBL & 288 & 439 & 333 & 192 & 196 & 335 & 270 & 373 & 319 \\
\hline HLRADIA-LBL & 3 & 4 & 5 & -6 & -7 & 3 & -1 & 0 & 2 \\
\hline \multirow[t]{2}{*}{ NBM-LBL } & 5 & 8 & 5 & 4 & 5 & 0 & 3 & 2 & 5 \\
\hline & \multicolumn{9}{|c|}{ SWUT $\left(\mathrm{W} \mathrm{m}^{-2}\right)$} \\
\hline LBL & 172 & 104 & 164 & 429 & 428 & 636 & 136 & 357 & 155 \\
\hline HLRADIA-LBL & 7 & 10 & 6 & 18 & 19 & 18 & 7 & 15 & 7 \\
\hline \multirow[t]{2}{*}{ NBM-LBL } & 0 & 0 & 0 & 2 & 1 & 37 & 0 & 25 & 0 \\
\hline & \multicolumn{9}{|c|}{ LWUT $\left(\mathrm{W} \mathrm{m}^{-2}\right)$} \\
\hline LBL & 304 & 293 & 281 & 231 & 229 & 242 & 248 & 280 & 286 \\
\hline HLRADIA-LBL & 6 & 6 & 6 & 4 & 5 & -27 & 6 & -20 & 7 \\
\hline NBM-LBL & -5 & -7 & -5 & -2 & -2 & -6 & -3 & -5 & -4 \\
\hline
\end{tabular}

HLRADIA was tested against NBM in a more complicated non-CIRC test case (defined by Geleyn et al., 2017), which contains two separate (precipitating) cloud layers with ice crystals and liquid droplets. For this case, there were large differences in the net LW flux and heating profiles for HLRADIA compared to NBM close to cloud boundaries and between the clouds. This is most likely due to HLRADIA's simplified treatment of the interactions between the cold and warm, vertically combined cloud decks above and below the level of the calculation. This case requires further study in order to ensure a clean comparison and analysis of factors related to the microphysical and optical properties of precipitating liquid, ice and mixed-phase clouds that are relevant for $\mathrm{LW}$ radiative transfer.

Overall, the off-line comparisons indicate that HLRADIA performs quite well for the surface radiative fluxes. However, the atmospheric clear-sky SW absorption is biased low, and rather large errors occur in net LW fluxes in the presence of clouds. The SW fluxes are sensitive to the way the effective size of cloud particles is treated.

\subsection{Ten-year validation of HIRLAM radiation fluxes}

In this section we present a validation of +3 and $+6 \mathrm{~h}$ Finnish Meteorological Institute HIRLAM operational forecasts against Jokioinen (WMO station 02963, latitude $60.814^{\circ} \mathrm{N}$, longitude $23.498^{\circ} \mathrm{E}$, elevation $103 \mathrm{~m}$ a.s.l.) and Sodankylä $\left(02836,67.362^{\circ} \mathrm{N}, 26.638^{\circ} \mathrm{E}, 179 \mathrm{~m}\right.$ a.s.l.) 3-hourly radiation observations, averaged from hourly means, between the 1 April 2006 and the 31 March 2016. Quality checked av- eraged SWDS and LWDS observations and the corresponding model output data for 2006-2016 used for the statistical comparison are available as a Supplement to this article. The station locations are shown in Fig. 4. The high-latitude Sodankylä observatory represents a sub-arctic boreal forest environment, while the Southern-Finland Jokioinen observatory is located in a rural environment consisting of agricultural, forest and town areas. The surroundings of both stations are flat. In addition to providing the standard SYNOP and TEMP observations from automatic weather station measurements and aerological soundings, both stations support an extensive observational programme for research, including solar and terrestrial radiation measurements.

In Sodankylä the instruments that provided the measurements used for this study are located on a measurement tower on the elevation of $18 \mathrm{~m}$ above an open surface outside the forest (http://litdb.fmi.fi/radiationtower.php). In both locations, the measurements are made at one minute interval. Their quality-controlled hourly averages were obtained from the FMI climate database. Global solar radiation (SWDS) is measured by Kipp\&Zonen CM11 pyranometers both in Jokioinen and in Sodankylä. For information about the SWDS measurements at Finnish stations see also Riihelä et al. (2015). Kipp\&Zonen CG4 pyrgeometers are used for the measurement of the upwelling and downwelling components of LW irradiance.

We focus on SWDS and LWDS results only as SWUS and LWUS are related to the description of surface properties rather than to atmospheric radiative transfer. Only cases 


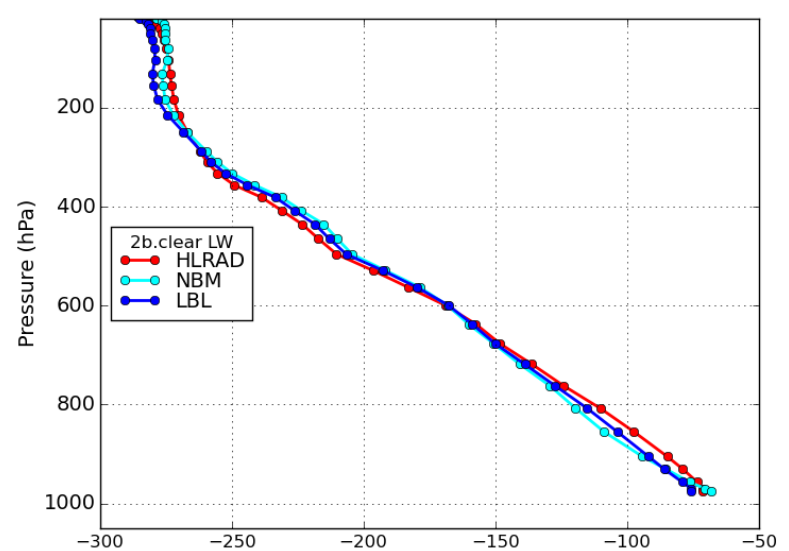

(a)

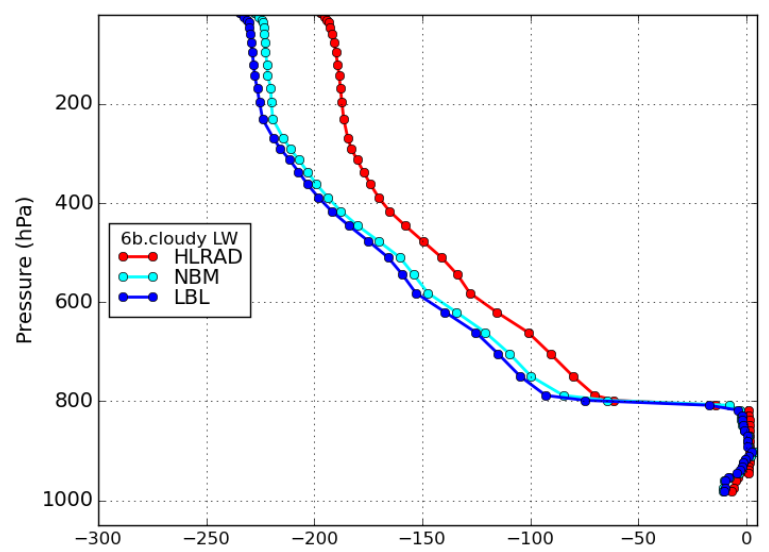

(c)

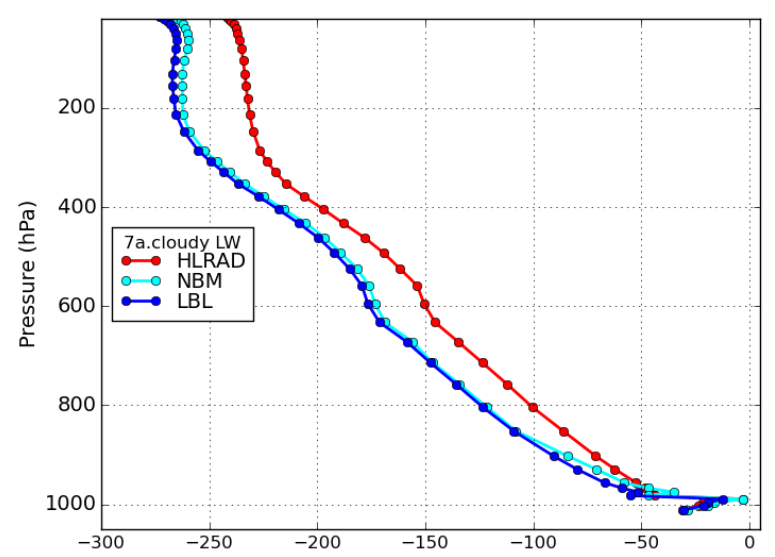

(e)

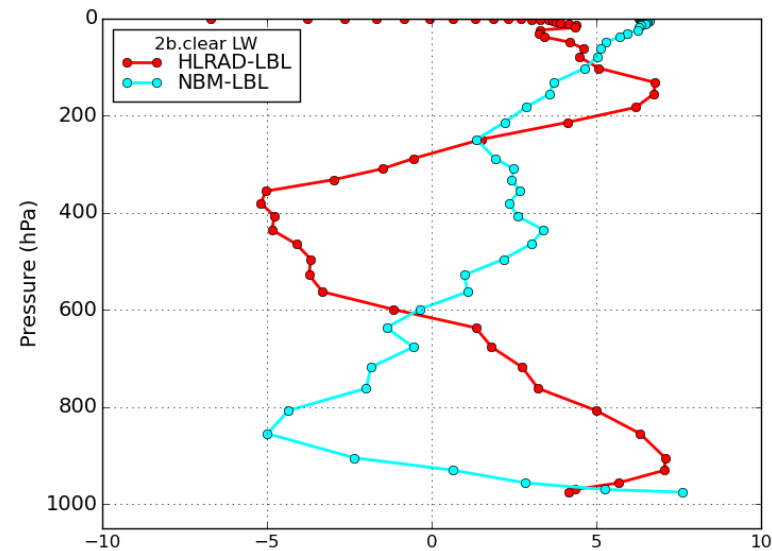

(b)

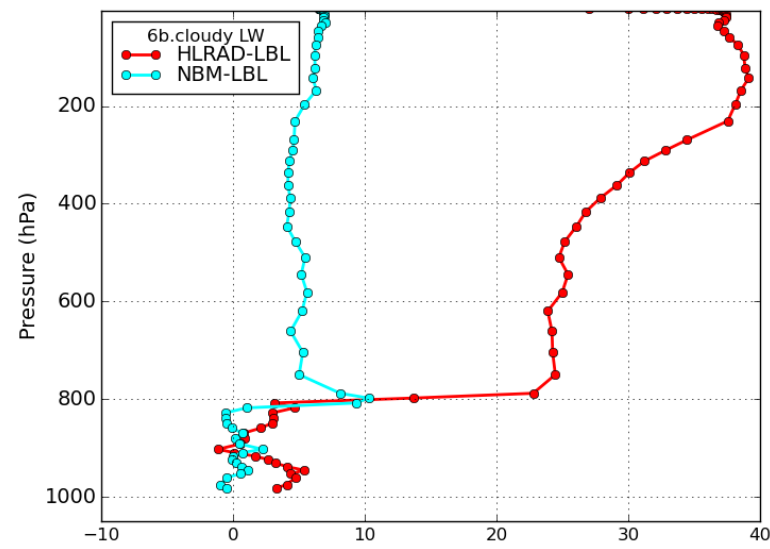

(d)

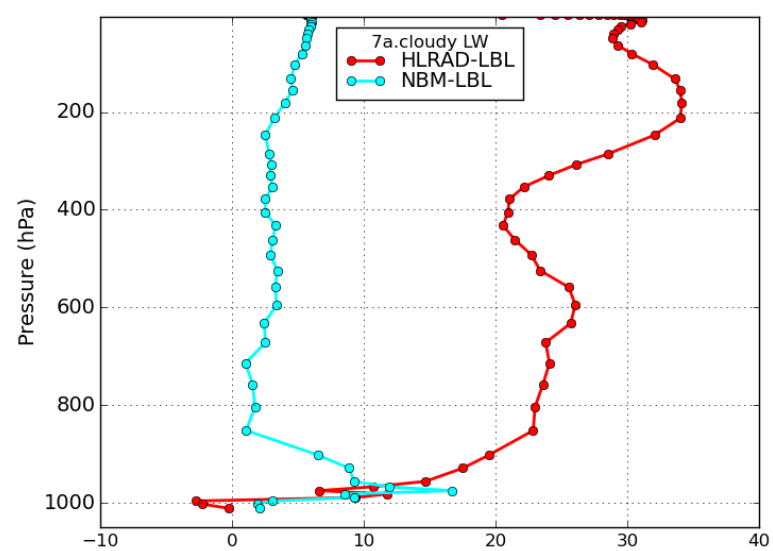

(f)

Figure 2. Net LW fluxes computed with LBL, HLRADIA and NBM (a, c, e) and the differences HLRADIA - LBL and NBM - LBL (b, d, f): $(\mathbf{a}, \mathbf{b})$ for case $2 \mathrm{~b},(\mathbf{c}, \mathbf{d})$ for case $6 \mathrm{~b}$ and $(\mathbf{e}, \mathbf{f})$ for case $7 \mathrm{a}$. Unit: $\mathrm{W} \mathrm{m}^{-2}$. 


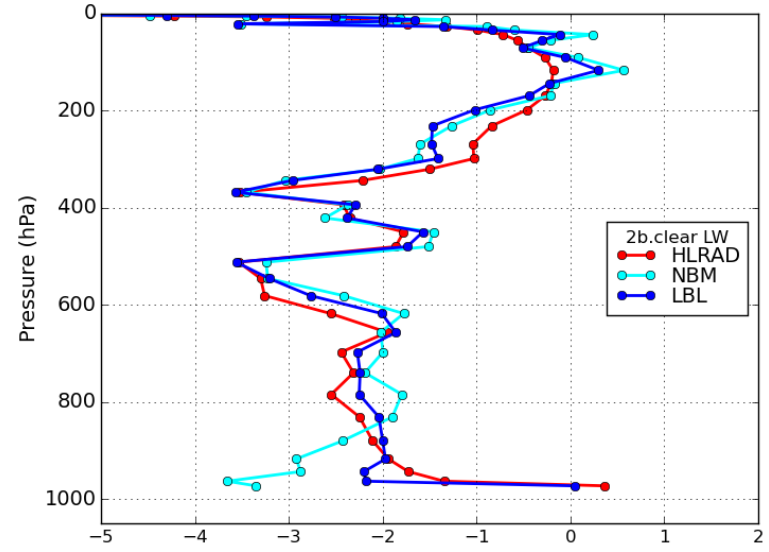

(a)

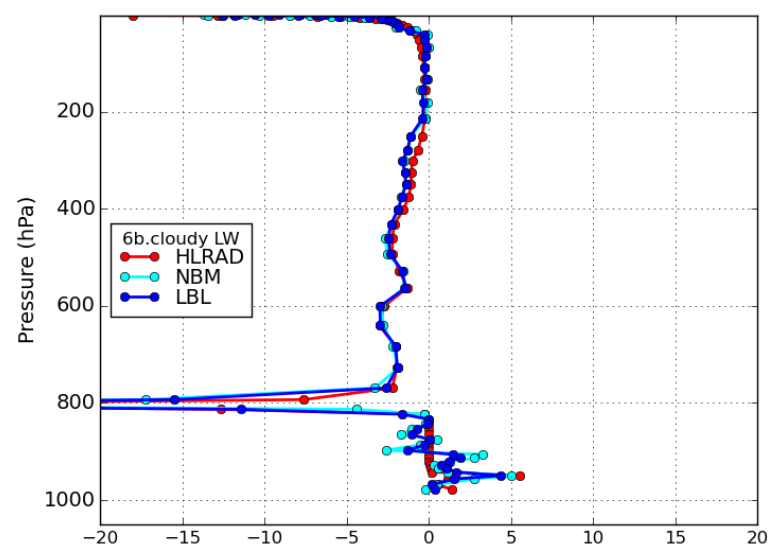

(c)

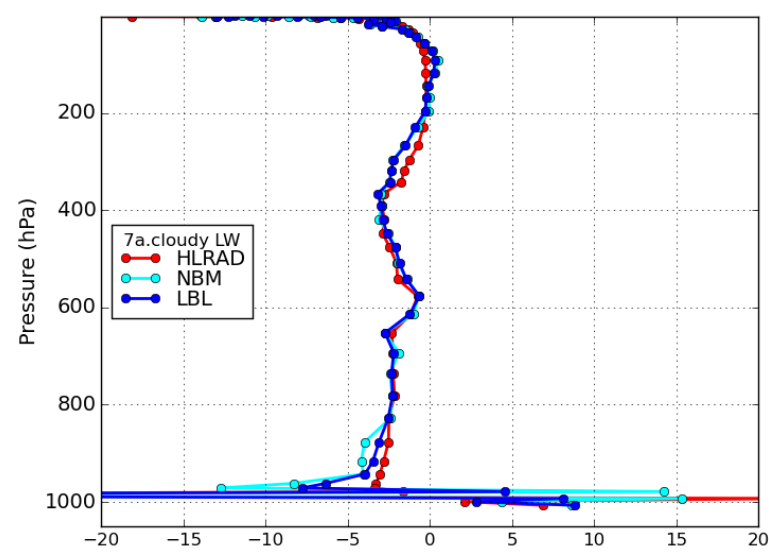

(e)

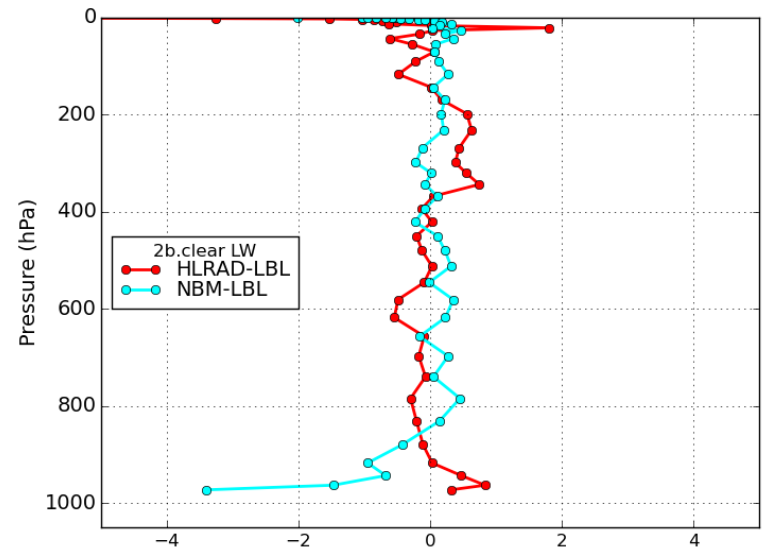

(b)

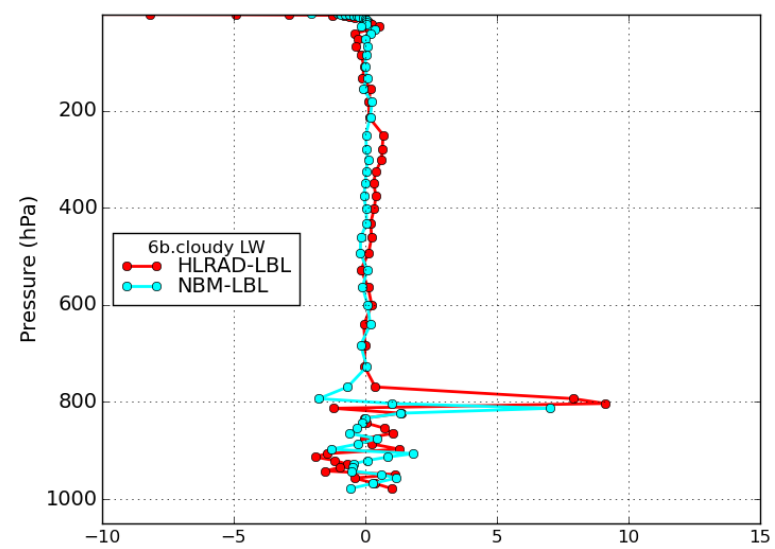

(d)

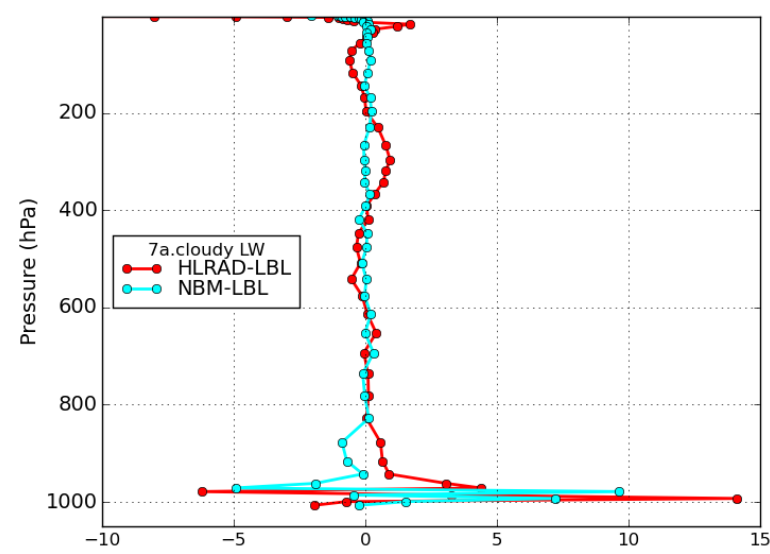

(f)

Figure 3. As for Fig. 2 but for LW heating rate (unit $\mathrm{Kday}^{-1}$ ). 


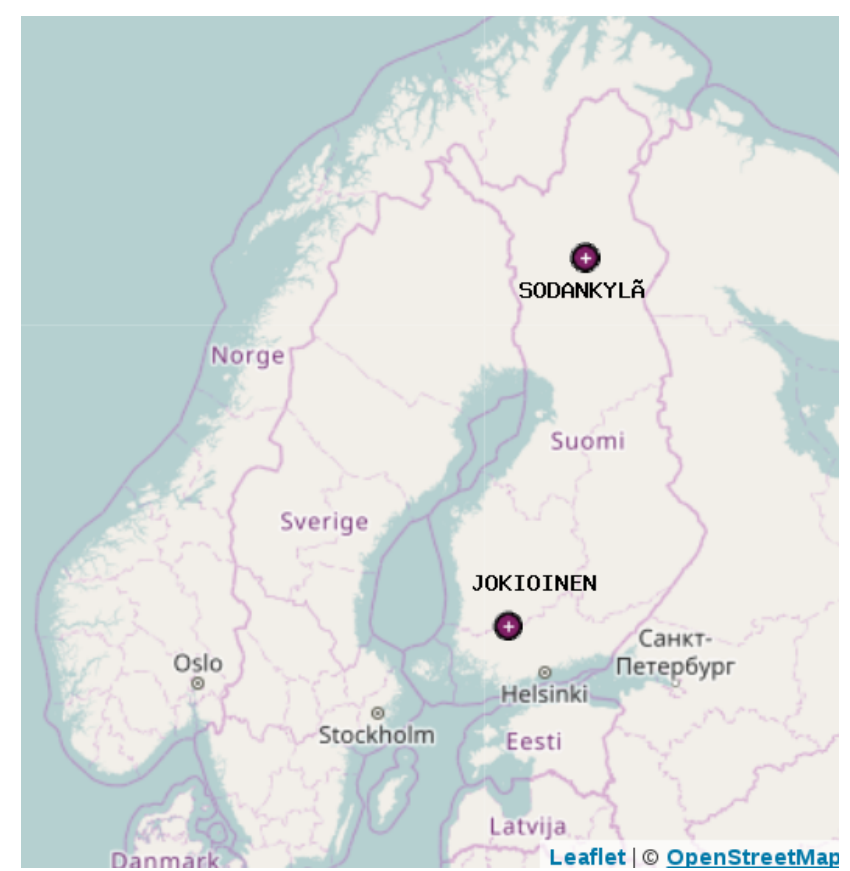

Figure 4. Location of the Finnish Meteorological Institute Jokioinen and Sodankylä observatories.

where the $3 \mathrm{~h}$ average $\mathrm{SWD}_{\mathrm{TOA}} \geq 1 \mathrm{~W} \mathrm{~m}^{-2}$ are included in the SWDS comparisons. Observed total cloudiness was used for classification of the sky conditions.

HLRADIA, used in the reference HIRLAM weather forecast model, which is applied operationally in FMI, has not changed since 2006 (see Table 1 in Eerola, 2013, for model updates), except that the $c_{\text {sur1 }}$ value was increased from 15 to $20 \mathrm{~W} \mathrm{~m}^{-2}$ when a new surface parametrization scheme was introduced in October 2010, and the orographic radiation parametrizations were added at the same time. The latter do not influence the results at the chosen observation sites which are surrounded by a flat forest and open field landscape. The FMI operational HIRLAM system is run with a grid spacing of $7 \mathrm{~km} / 65$ levels in the horizontal/vertical directions.

HLRADIA in HIRLAM differs from the HARMONIEAROME version described in Sect. 3 and used in the CIRC comparisons (Sect. 4.1) regarding a few details. In HIRLAM, the original aerosol treatment based on coefficients $a_{\mathrm{a}}=1.20$ and $a_{\mathrm{s}}=1.25$ in Eq. (1) is used. Cloud ice crystal size $r_{\mathrm{e}}$,ice and shape are parametrized according to Ou and Liu (1995); Wyser et al. (1999). A cloud inhomogeneity correction of $20 \%$ is applied for SW calculations as explained in Sect. 2. Clear-sky diffuse radiation is diagnosed according to Eq. (5), not with the new formulations suggested for HARMONIEAROME (Sect. 3.2). Surface albedo and emissivity are obtained as described by Unden et al. (2002).

\subsubsection{SWDS}

Differences between forecast and observed SWDS irradiance are related to several factors: (1) how well the timedependent atmospheric and surface state (i.e. cloud distribution and microphysical properties, and to a minor extent, aerosol and water vapour content and surface albedo which influences reflections between clouds and the surface) are described in the model, (2) how well the atmospheric radiation parametrizations perform for different atmospheric conditions, (3) how reliable and representative the observed radiation fluxes are, and (4) how good are the validation methods. Observation errors are presumed to be small compared to the overall variance of SWDS (but not necessarily compared to the systematic difference between observations and model output). A typical measurement error in hourly global radiation measurements is of the order of $5 \%$ (Lindfors et al., 2007; Riihelä et al., 2015). When the solar elevation is low, the uncertainty in the measurements is larger. In the case of SWDS, the measurements and the model represent, in principle, the same spatial and time scales. The validation process contains time-averaging, which is done in a similar manner for both the observations and the model output. In the validation presented here, for the selected locations, interpolations are not applied and the validation method may be considered to be reliable. The differences between forecast and observed SWDS are thus most likely related to the uncertainties of the model (1 and 2 above).

The SWDS statistics differ between Jokioinen and Sodankylä: there is an overall positive bias of $20 \mathrm{~W} \mathrm{~m}^{-2}$ at Jokioinen while for Sodankylä the bias is small and negative (i.e. $-1 \mathrm{~W} \mathrm{~m}^{-2}$; Table 3). This is also illustrated in Figs. 5 and 6. The highest SWDS values are overestimated; smaller values tend to be underestimated. Figure 6 shows a large scatter at all times of the day. The scatter is smaller, especially at Jokioinen, when only clear-sky cases are included but the overestimation remains (not shown).

Cloudy and clear sky cases were classified according to the observed total cloud cover using a clearness index (CSI8), which was defined as CSI $8=1-N_{\mathrm{cl}} / 8$. Here "cloudy" means that CSI $8<0.3$ and "clear" implies that CSI $8>0.7$ (or $>0.8$ in the solar elevation comparisons, see below), where $N_{\mathrm{cl}}$ is the cloudiness in octas. For the cloudy cases a positive bias is observed during each season at both locations, except September-November (SON) and DecemberFebruary (DJF) at Sodankylä (Table 3). However, for the clear cases the bias is negative at Sodankylä for each season but positive in Jokioinen. The largest clear-sky positive biases at Jokioinen are found in spring (MAM) and summer (JJA). It might be partly related to the increased aerosol load due to dust and pollen, which was not accounted for by HLRADIA.

The correlation between forecasts and observations varies from 0.81 to 0.89 for the cloudy cases and from 0.94 to 0.98 for the clear cases (Table 3 ). The correlations are slightly bet- 
Table 3. HIRLAM forecast versus observed SWDS (unit $\mathrm{W} \mathrm{m}^{-2}$ ) at Jokioinen and Sodankylä for 2006-2016 classified according to CSI8. Bias, standard deviation of the error (SDe) and correlation (corr) are shown for all months (ALL), December-January-February (DJF) and the other three seasons (JJA, SON, MAM). $N$ is the number of cases.

\begin{tabular}{llrrrr|rrrr}
\hline & & \multicolumn{3}{c}{ Jokioinen } & \multicolumn{4}{c}{ Sodankylä } \\
\cline { 2 - 10 } & sky & bias & SDe & corr & $N$ & bias & SDe & corr & $N$ \\
\hline \multirow{2}{*}{ ALL } & all & 20.2 & 72.4 & 0.94 & 17195 & -1.0 & 74.6 & 0.91 & 16487 \\
& cloudy & 24.4 & 81.4 & 0.90 & 8692 & 4.0 & 77.4 & 0.85 & 9529 \\
& clear & 13.9 & 48.1 & 0.98 & 3680 & -8.2 & 56.6 & 0.96 & 4243 \\
\hline \multirow{2}{*}{ DJF } & all & 7.0 & 25.5 & 0.92 & 2739 & -0.6 & 17.3 & 0.93 & 1357 \\
& cloudy & 8.4 & 27.6 & 0.89 & 1935 & -0.2 & 17.1 & 0.87 & 908 \\
& clear & 2.6 & 18.7 & 0.98 & 397 & -2.8 & 18.5 & 0.95 & 320 \\
\hline \multirow{2}{*}{ MAM } & all & 34.4 & 75.2 & 0.94 & 4523 & -0.7 & 74.5 & 0.91 & 4769 \\
& cloudy & 44.2 & 89.9 & 0.90 & 2140 & 5.5 & 77.9 & 0.86 & 2497 \\
& clear & 21.1 & 45.2 & 0.98 & 1203 & -8.8 & 56.8 & 0.96 & 1484 \\
\hline \multirow{2}{*}{ JJA } & all & 23.8 & 90.8 & 0.93 & 5881 & 1.2 & 90.9 & 0.89 & 6593 \\
& cloudy & 36.2 & 113.8 & 0.85 & 2162 & 8.1 & 99.1 & 0.81 & 3566 \\
& clear & 14.5 & 56.2 & 0.97 & 1347 & -5.5 & 63.4 & 0.96 & 1655 \\
\hline \multirow{2}{*}{ SON } & all & 4.2 & 51.2 & 0.92 & 3562 & -6.9 & 44.2 & 0.89 & 3228 \\
& cloudy & 4.9 & 53.9 & 0.85 & 2197 & -4.4 & 42.8 & 0.81 & 2262 \\
& clear & 1.8 & 42.9 & 0.96 & 599 & -13.9 & 43.2 & 0.94 & 654 \\
\hline
\end{tabular}

ter for Jokioinen than Sodankylä. The standard deviation of the error, a measure of the random error, is largest for' the cloudy cases in spring and summer. This is most probably due to inaccurate representation of scattered cloudiness by HIRLAM. The results are qualitatively similar but the numbers differ when other clear sky indexes, based on observed SWDS, are applied for classification (not shown). Because of the difference between observed and simulated cloudiness, the results could be different if the total cloud cover by HIRLAM had been used as the basis for classification. Comparison between observed and simulated cloud cover is left for a further study because the latter was not available for this study for technical reasons.

What is the reason for the negative bias in clear-sky SWDS at Sodankylä and the prevailing positive bias in cloudy-sky SWDS at both locations? Do the HIRLAM (clear-sky) radiation parametrizations underestimate SWDS systematically when the sun is low and overestimate it when the sun is high? Could the difference between the locations be related to real vs. assumed aerosol effects? Are the HIRLAM clouds too transparent because their grid-average cloud condensate content is too small (and additionally reduced by the inhomogeneity assumption) or because the radiative transfer through clouds is inaccurate? Too few (low) clouds or clouds that are too thin might show up as a negative bias in the LWDS validation (but a positive bias prevails there, see Sect. 4.2.2). The comparisons of clear-sky SWDS could be influenced by spurious clouds in the model simulation, which would make the bias slightly more negative and increase the random error. Next we will consider the impact of solar elevation, discuss some problems of observed vs. simulated cloudiness and address shortly the impact of aerosols.

Solar elevation is represented by $\mathrm{SWD}_{\mathrm{TOA}}$. The overall bias in SWDS relative to observations is negative $(-4 \%)$ at Sodankylä and positive $(9 \%)$ at Jokioinen when SWD is between 1 and $400 \mathrm{~W} \mathrm{~m}^{-2}$ (we use this range to define low solar elevation) and all cloudy and clear sky conditions are included. At both locations, more than half of all the data falls into the category of low solar elevation, while at Jokioinen there are more cases with high solar elevation $\left(\mathrm{SWD}_{\mathrm{TOA}}>800 \mathrm{~W} \mathrm{~m}^{-2}\right)$. For clear-sky conditions (for this particular comparison defined more strictly by CSI8 $>0.8$ ), the average SWDS estimated from observations/forecasts was $272 / 286 \mathrm{~W} \mathrm{~m}^{-2}$ for Jokioinen and $230 / 222 \mathrm{~W} \mathrm{~m}^{-2}$ for Sodankylä, i.e. the values are larger and the bias is positive at Jokioinen whereas the values are smaller and the bias is negative at Sodankylä.

Table 4 shows that for all categories of $\mathrm{SWD}_{\mathrm{TOA}}>1 \mathrm{~W} \mathrm{~m}^{-2}$, the HIRLAM clear-sky SWDS is smaller than observed at Sodankylä and especially so when the sun is close to the horizon $\left(\mathrm{SWD}_{\mathrm{TOA}}<100 \mathrm{~W} \mathrm{~m}^{-2}\right)$. In Jokioinen, the relative bias is slightly negative only in these cases. The lower the elevation, the larger the relative bias and the smaller the correlation between the observations and forecasts. A smaller correlation is expected also because the variation of solar elevation is the main source of SWDS variation. Limiting the range of solar angles in the sample is thus likely to lead to decreasing correlation. The smallest correlation when $\mathrm{SWD}_{\mathrm{TOA}}>800 \mathrm{~W} \mathrm{~m}^{-2}$ might also be related to differences in observed and simulated scattered 


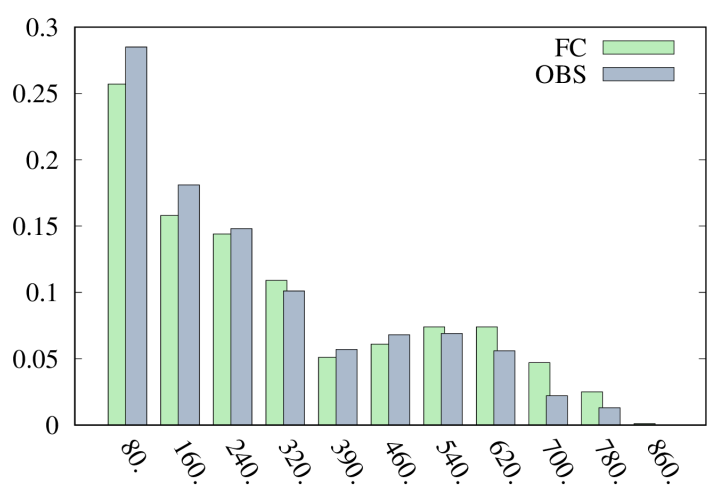

(a)

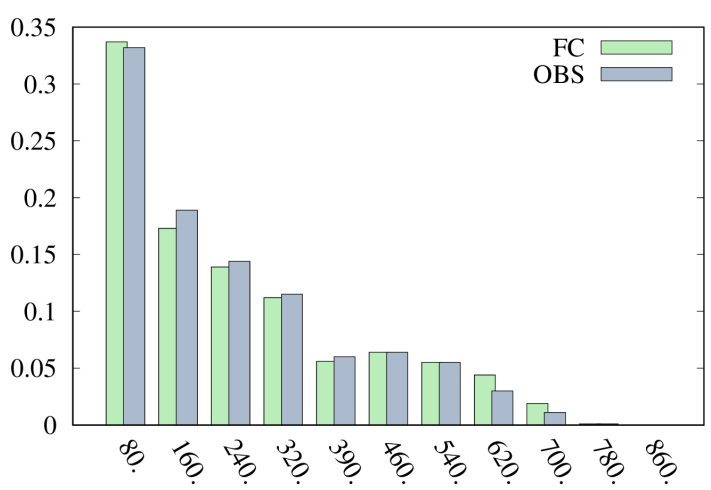

(b)

Figure 5. Observed (grey) and forecast (green) SWDS distribution using all available data between April 2006 and March 2016: (a) Jokioinen (b) Sodankylä. Units on $x$-axis: $\mathrm{W} \mathrm{m}^{-2}$, on $y$-axis: relative frequency $[0,1]$.

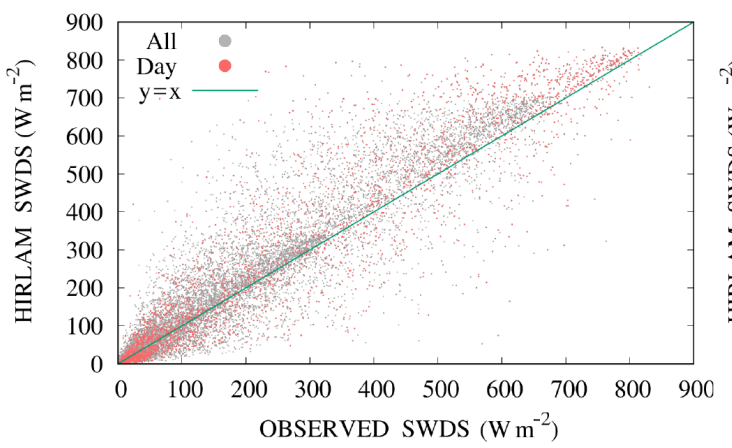

(a)

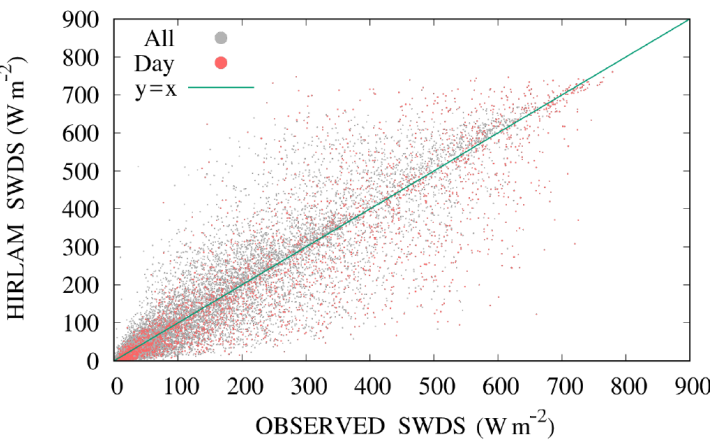

(b)

Figure 6. All predicted vs. observed SWDS: (a) Jokioinen and (b) Sodankylä. Afternoon fluxes (11:00-14:00 UTC or 12:00-15:00 local time) are shown in red, grey dots denote all times.

cloudiness during summer daytime conditions. The random error (relative standard deviation of the error) also increases with decreasing solar elevation. A larger relative bias may indicate the increasing inaccuracy with decreasing solar elevation both in the observations and in the model. Hence the clear-sky negative bias depends on solar elevation but is not fully explained by it.

The different biases in clear-sky SWDS (positive for Jokioinen, negative for Sodankylä), could be partly related to different methods of cloud detection. During the period 2006-2016 analyzed here, a shift from visual cloud observations to ceilometer cloud observations occurred at both sites, but earlier in Sodankylä (February 2008) than in Jokioinen (January 2013). Considering the period January 2013-March 2016, when ceilometers were used at both sites, the relative clear-sky bias in Jokioinen was 5.0\% (compared to $4.8 \%$ for the whole period; Table 4 ) and $-0.3 \%$ at Sodankylä (compared to $-3.4 \%$ for the whole period). The corresponding random errors were $19 \%(16.5 \%)$ and $23 \%(24.5 \%)$, respectively. Thus, considering the ceilometer era only, the clear-sky SWDS bias is still more positive at
Jokioinen than Sodankylä, but the difference is smaller than that for the whole period of observations. Furthermore, the large random errors suggest some cloud contamination in either the HIRLAM forecasts or in observations.

In order to detect the possible impact of aerosols, HIRLAM SWDS at Jokioinen was compared to observations for July-August only. In the basic HLRADIA parametrization, the aerosol-related coefficients for SWDS should be a better representation of the typical rural conditions of Jokioinen than those of Sodankylä subarctic nature. During 2010 the aerosol loads were significantly higher than usual in Southern Finland due to Russian forest fires (Toll et al., 2016). Under these conditions there should have been more black carbon in the air than assumed by the simple aerosol parametrizations in HLRADIA. However, it was not possible to find a clear indication of an increased positive bias in SWDS for the clear sky cases with low or high solar angles, compared to the other summers (not shown). Arola et al. (2007) showed that during a spring 2006 high aerosol load episode at Jokioinen, the largest aerosol effects were seen at 
Table 4. HIRLAM forecast versus observed clear sky SWDS at Jokioinen and Sodankylä classified according to $\mathrm{SWD}_{\mathrm{TOA}}$ (unit $\mathrm{W} \mathrm{m}^{-2}$ ) for April 2006-March 2016.

\begin{tabular}{lrrrr|rrrrr}
\hline & \multicolumn{5}{c}{ Jokioinen } & \multicolumn{4}{c}{ Sodankylä } \\
\cline { 2 - 9 } mask & $\begin{array}{r}\text { rel.bias } \\
\%\end{array}$ & $\begin{array}{r}\text { rel.SDe } \\
\%\end{array}$ & correl & $N$ & $\begin{array}{r}\text { rel.bias } \\
\%\end{array}$ & $\begin{array}{r}\text { rel.SDe } \\
\%\end{array}$ & correl & $N$ \\
\hline SWD $_{\text {TOA }}>1$ & 4.8 & 16.5 & 0.981 & 3289 & -3.4 & 24.8 & 0.962 & 4128 \\
\hline $\mathrm{SWD}_{\text {TOA }}<50$ & -5.6 & 35.9 & 0.806 & 444 & -22.5 & 53.9 & 0.740 & 681 \\
$\mathrm{SWD}_{\mathrm{TOA}}<100$ & -0.9 & 30.0 & 0.896 & 694 & -9.8 & 42.3 & 0.872 & 1067 \\
$\mathrm{SWD}_{\mathrm{TOA}}<200$ & 0.4 & 32.1 & 0.925 & 1025 & -5.9 & 38.3 & 0.900 & 1665 \\
$\mathrm{SWD}_{\mathrm{TOA}}<400$ & 3.6 & 23.3 & 0.964 & 1682 & -5.6 & 33.8 & 0.937 & 2418 \\
$\mathrm{SWD}_{\mathrm{TOA}}>800$ & 5.0 & 9.9 & 0.784 & 504 & -2.4 & 15.3 & 0.541 & 310 \\
\hline
\end{tabular}

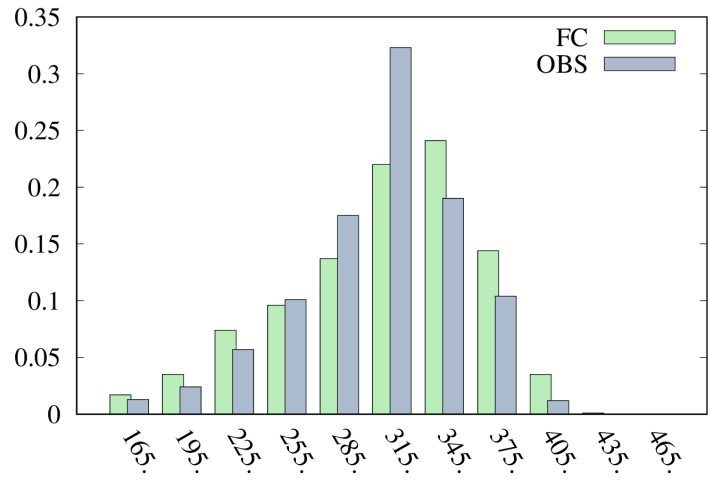

(a)

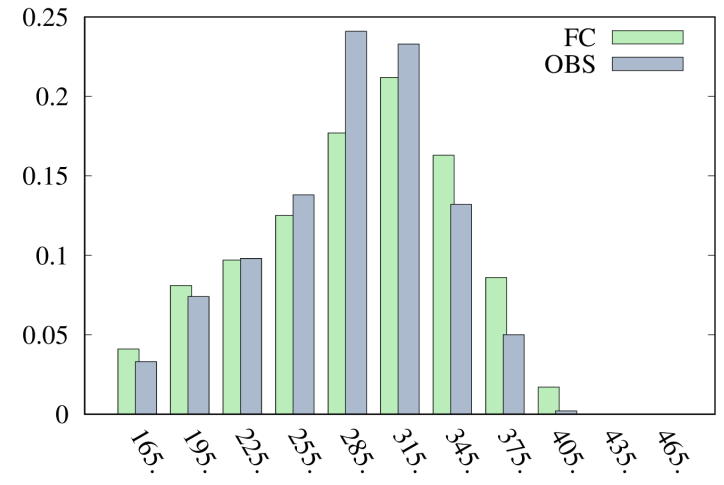

(b)

Figure 7. Observed (grey) and forecast (green) LWDS distribution over all available data: (a) Jokioinen (b) Sodankylä. Units on $x$-axis: $\mathrm{W} \mathrm{m}^{-2}$, on $y$-axis: relative frequency $[0,1]$.

the UV wavelengths and not so much in the visible or near infrared, which dominate the low tropospheric SW irradiance.

In summary, the biases in clear-sky SWDS at both locations were more negative at low solar elevation angles. However, overall the biases were more positive at Jokioinen than Sodankylä regardless of cloud-cover. We have not found a conclusive reason for this but in the case of clear-sky SWDS the differences may be due to differences in cloud detection methodologies and might be partly linked to assumptions made about aerosols. The impact of biases in modelled cloudiness should be investigated in the future.

\subsubsection{LWDS}

Similarly to SWDS, observed and forecast LWDS depend on the state of the atmosphere - mainly on cloud distribution and microphysical properties, temperature, water vapour and, to a lesser extent, aerosol content. Thus, the difference between forecast and observed LWDS is related to the same factors as for SWDS. LWDS measurements contain more sources of uncertainty than measurements of SWDS especially in cold Northern Hemisphere winter conditions. On the other hand, the LWDS flux is more isotropic and does not depend on such factors as solar elevation.

HIRLAM shows a small overall positive bias of 4$5 \mathrm{~W} \mathrm{~m}^{-2}$ in LWDS at both locations. The bias is positive for each season except DJF at Sodankylä. The contribution of cloudy and clear sky fluxes to the positive bias differs: the clear cases seem to contribute more at Sodankylä while at Jokioinen the cloudy cases are the main source of the bias (Table 5). The results are more representative at Sodankylä, where LW measurements are available for all the years of the comparison April 2006-March 2016 while at Jokioinen they only became available in May 2013. However, a comparison limited to the period between May 2013 and March 2016, when the cloud observations were made by a ceilometer at both locations and the enhanced $c_{\text {sur } 1}=20 \mathrm{~W} \mathrm{~m}^{-2}$ was applied in the LW parametrizations, confirms the result. The mean forecast/observed LWDS was $308 / 304 \mathrm{~W} \mathrm{~m}^{-2}$ at Jokioinen and $289 / 283 \mathrm{~W} \mathrm{~m}^{-2}$ at Sodankylä, calculated using 7881 and 7884 cases respectively. During this period, there were more clear-sky and less cloudy cases at Jokioinen (2469 clear vs. 4368 cloudy cases) compared to Sodankylä (2027 vs. 4870). The clear cases contributed to the overall 
Table 5. As in Table 3 but for LWDS. In Jokioinen, LW observations represent the period from May 2013 to March 2016, at Sodankylä, from April 2006 to March 2016.

\begin{tabular}{llrrrr|rrrr}
\hline & & \multicolumn{5}{c|}{ Jokioinen } & \multicolumn{4}{c}{ Sodankylä } \\
\cline { 3 - 10 } sky & mask & bias & SDe & corr & $N$ & bias & SDe & corr & $N$ \\
\hline \multirow{2}{*}{ ALL } & all & 4.28 & 21.50 & 0.92 & 8349 & 4.87 & 26.37 & 0.89 & 26256 \\
& cloudy & 5.29 & 22.57 & 0.88 & 4552 & 1.11 & 25.65 & 0.88 & 15593 \\
& clear & 2.91 & 18.14 & 0.95 & 2668 & 10.80 & 25.30 & 0.91 & 6143 \\
\hline \multirow{2}{*}{ DJF } & all & 2.51 & 24.27 & 0.91 & 2174 & -2.24 & 27.79 & 0.85 & 6560 \\
& cloudy & 2.73 & 25.55 & 0.86 & 1611 & -5.80 & 27.52 & 0.82 & 4411 \\
& clear & 1.21 & 17.41 & 0.91 & 362 & 3.07 & 26.05 & 0.70 & 1137 \\
\hline \multirow{2}{*}{ MAM } & all & 1.34 & 19.62 & 0.92 & 1580 & 7.01 & 24.40 & 0.88 & 6510 \\
& cloudy & 5.78 & 20.09 & 0.87 & 723 & 3.71 & 23.92 & 0.83 & 3370 \\
& clear & -2.26 & 16.44 & 0.93 & 643 & 11.40 & 22.76 & 0.87 & 1997 \\
\hline \multirow{2}{*}{ JJA } & all & 5.98 & 18.12 & 0.85 & 2190 & 9.05 & 23.58 & 0.79 & 6568 \\
& cloudy & 7.52 & 18.41 & 0.77 & 833 & 6.20 & 22.25 & 0.77 & 3582 \\
& clear & 4.86 & 16.20 & 0.85 & 970 & 13.90 & 23.08 & 0.78 & 1732 \\
\hline \multirow{2}{*}{ SON } & all & 7.22 & 22.10 & 0.88 & 2177 & 5.05 & 27.31 & 0.83 & 6075 \\
& cloudy & 7.79 & 21.42 & 0.84 & 1246 & 2.03 & 26.04 & 0.81 & 3952 \\
& clear & 6.37 & 21.31 & 0.88 & 630 & 11.30 & 28.63 & 0.81 & 1115 \\
\hline
\end{tabular}

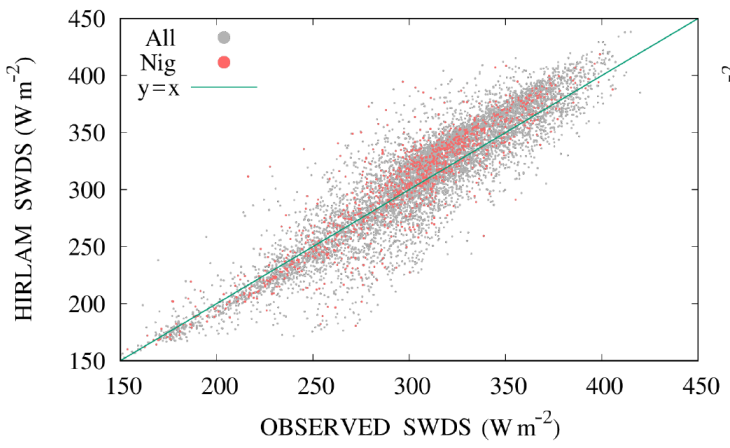

(a)

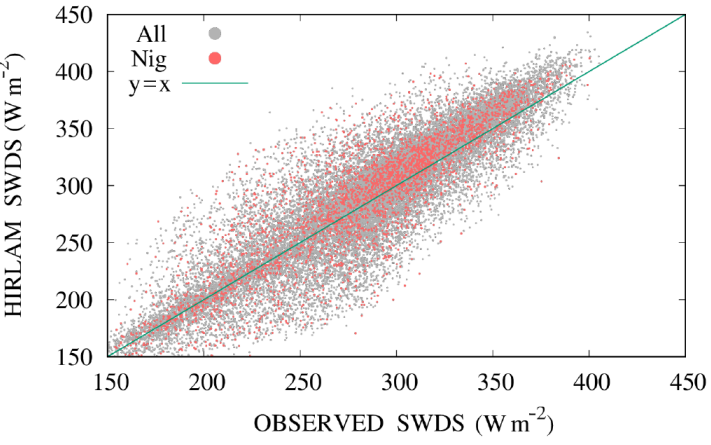

(b)

Figure 8. All predicted vs. observed LWDS: (a) Jokioinen and (b) Sodankylä. Night-time fluxes (23:00-02:00 UTC or 00:00-03:00 local time) are shown in red, grey dots denote all times.

bias by ca. $3 \mathrm{~W} \mathrm{~m}^{-2}$ at Sodankylä and by ca. $1 \mathrm{~W} \mathrm{~m}^{-2}$ at Jokioinen.

Both the distribution (Fig. 7) and the scatter plot (Fig. 8) indicate that the positive bias is due to the large LWDS values. These might be related to low clouds and/or relatively warm and moist near-surface air, which may occur in HIRLAM more frequently than observed. Evaluating the distribution of LWDS including only clear sky cases observed at Sodankylä shows that the number of the large values is clearly overestimated compared to observations, and the number of small values is underestimated (not shown). Another possibility is that, especially in cases of large LWDS, the radiative transfer is inaccurate in HLRADIA. For example, the additional term $c_{\text {surl } 1}$ (Eq. 7) may be tuned to values that are too high in warm, moist conditions and/or under clouds. The increased positive bias in LWDS for warmer or moister conditions is consistent with the findings of Räisänen et al. (2000a), which show net LW fluxes that are too high in clear-sky comparisons relative to reference results in tropical conditions, and too low in subarctic conditions. In addition, the CIRC LWDS results also indicate this (Table 2, compare for example the moist and warm experiments $2 b$ and $3 b$ to the dry and cold experiments $4 b$ and $5 b$ ).

\subsection{A MarcoPolo sensitivity example}

The sensitivity of the HARMONIE-AROME NWP model results to the choice of radiation scheme and its calling frequency is illustrated by the results of experiments that were run for a domain over China around Shanghai for 


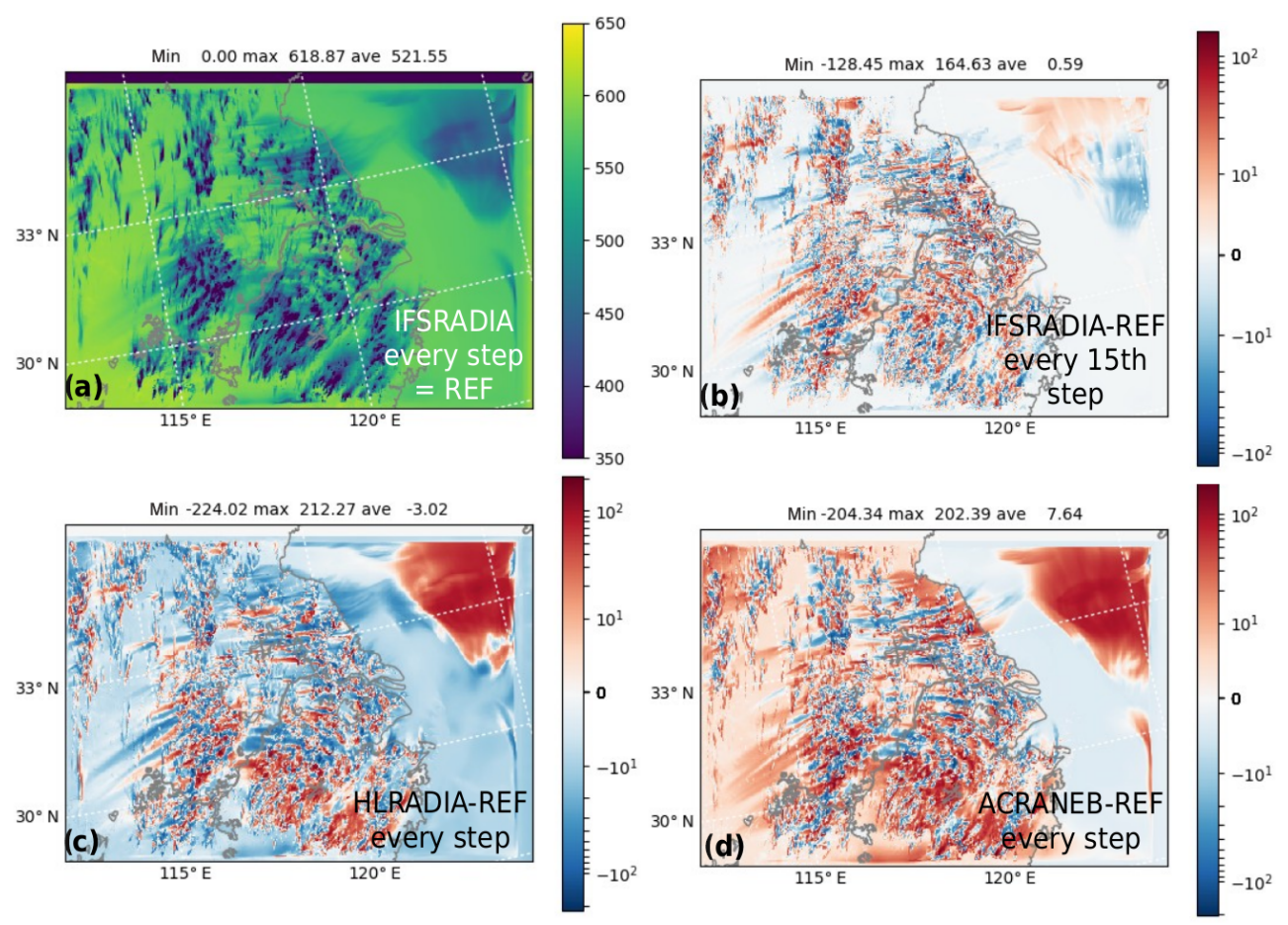

Figure 9. Average downwelling global radiation (SWDS, $\mathrm{W} \mathrm{m}^{-2}$ ) over the Shanghai area according to the HARMONIE-AROME 00:00 UTC $+12 \mathrm{~h}$ forecast for the 7 July 2010: (a) reference IFSRADIA (REF) called at every time step, (b) difference of IFSRADIA (IFS) called at every 15 th time step from REF, IFS - REF, (c) HLRADIA called at every time step - REF, (d) ACRANEB called a every time step - REF.

a convective case at the 30 July 2010. These experiments utilized the HARMONIE-AROME setup prepared for the project "MarcoPolo" (Nielsen et al., 2017). MarcoPolo was an international collaboration project funded by the EU 7th framework programme. The focus of the MarcoPolo project (2014-2017) was on assessments of anthropogenic and natural emissions of gases and aerosols in China. The improved emission inventories were used for improving air quality modelling and weather forecasts at urban and regional scales

Figure 9a shows SWDS (global radiation) averaged over $12 \mathrm{~h}$ over the domain when HARMONIE-AROME used the default IFSRADIA scheme, run at every time step $(1 \mathrm{~min})$. The difference between IFSRADIA run every 15th time step from the one-minute reference (Fig. 9b) shows a shift of the location of the maximum and minimum values, but this does not influence the area averages. A difference in area-averages is also seen when HLRADIA (Fig. 9c) or ACRANEB (Fig. 9d), called at every time step, are compared to IFSRADIA called at every time step. A map of LWDS showed similar features but the magnitude of maximum differences between the cases was smaller (not shown). Figure 10a and $\mathrm{b}$ show the corresponding differences in the accumulated (convective) precipitation due to the IFSRADIA calling frequency. Local differences are large but the area averages are not affected unless HLRADIA (Fig. 10c) or ACRANEB (Fig. 10d) are used - then the amount of pre- cipitation decreases. The total cloudiness after $12 \mathrm{~h}$ of integration (at 20:00 local time, not shown) also indicated large spatial differences due to the IFSRADIA calling frequency and a decrease in the area-averaged cloudiness for HLRADIA and ACRANEB compared to IFSRADIA.

This preliminary case study shows that the HARMONIEAROME results are quite sensitive to the calling frequency and choice of the radiation parametrizations. Further, more systematic studies are needed to understand the significance of such differences for weather forecasts and to validate the results against observed radiation fluxes and standard meteorological observations.

\section{Conclusions}

We have documented and evaluated the latest version of HLRADIA, a broadband radiation transfer scheme for mesoscale NWP models, recently prepared for use in the HARMONIE-AROME NWP system. The scheme was tested against CIRC benchmark cases, and found to perform reasonably accurately in clear-sky SW and LW radiation calculations compared to LBL and NBM results. Furthermore, a 10-year comparison of HIRLAM downwelling SW and LW fluxes provided by the HLRADIA scheme showed that the model performed well compared to surface measurements at two Finnish meteorological stations. Therefore, overall the 

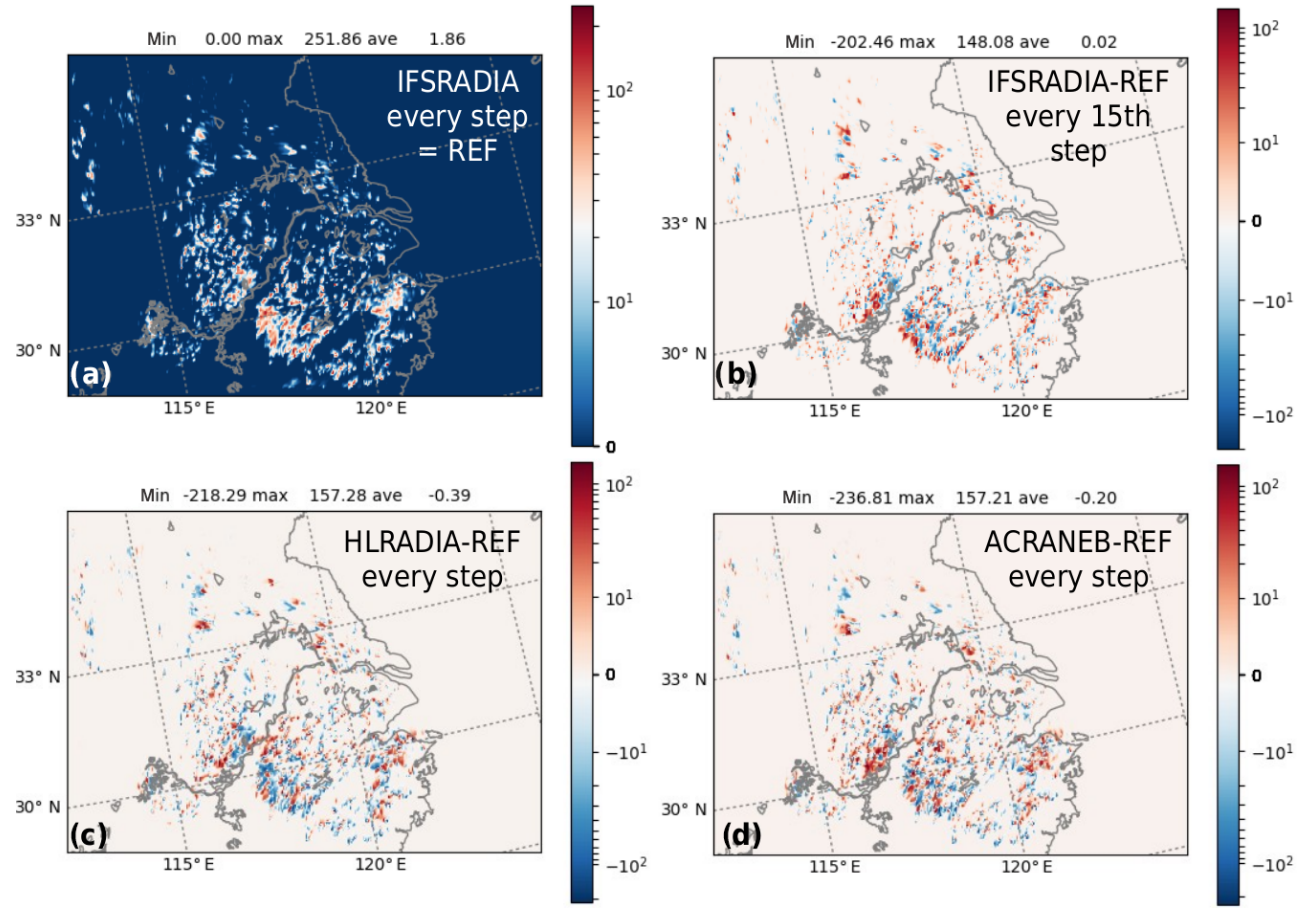

Figure 10. As Fig. 9 but for accumulated rain (mm/12 h).

performance of HLRADIA can be considered sufficiently good, especially considering the simplicity of the scheme. Yet, as detailed below, a number of biases and issues were identified that need attention in future studies.

A systematic underestimation of the clear-sky SW absorption was found in HLRADIA relative to the LBL results for the CIRC intercomparison experiments. This indicates that the equation for SW heating in the atmosphere may need revision. In the cloudy cases, even larger overestimations of SWDS and the outgoing SW flux at the top of atmosphere were detected. The SW results are particularly sensitive to the definition of cloud droplet size. The parametrization of cloud droplet size may lead to biases in downwelling fluxes at the surface and in the net fluxes throughout the atmosphere.

An overestimation of SWDS, especially under cloudy conditions, was indicated also by the 10-year comparison. This suggests that in the reference HIRLAM system the cloud optical thickness has been too large, partly because a too large cloud inhomogeneity correction is applied by default. At low solar angles, the clear-sky SWDS fluxes seem to be underestimated compared to observations. However, the observation errors related to radiation fluxes also increase with decreasing solar elevation. The impact of the treatment of aerosols on SWDS was suspected to be a factor, but this could not be shown using the present statistics. The random error in SWDS was large, especially in spring and summer, presumably due to highly variable scattered cloudiness. Such an er- ror is related to uncertainty both in the observed and simulated cloudiness and cloud properties.

Clear-sky biases in downward LW flux at the surface were positive in the CIRC comparisons, except for the cases where the atmosphere was cold and dry. For the cloudy cases the biases were smaller and positive. However, HLRADIA overestimated the cloud LW radiative effect at the TOA compared to the LBL reference. The net LW fluxes above the cloud were also clearly overestimated. In terms of the LW budget, the atmosphere lost less energy in HLRADIA than in the LBL model. This overestimation was of the same order of magnitude as the maximum underestimation of the SW absorption.

An overestimation of LWDS was also detected in the 10year comparison, where HIRLAM showed a small overall positive bias of $4-5 \mathrm{~W} \mathrm{~m}^{-2}$ in LWDS at Jokioinen and Sodankylä. The positive bias was mainly due to large LWDS values, which originate in cloudy and/or warm and humid boundary layer conditions. This bias can be at least partly explained by the use of an empirical correction for greenhouse gases and aerosols which was too large. This had been tuned in order to improve the surface energy balance simulated by HIRLAM in cold, dry conditions. Simplifications to the interactions between atmospheric layers and a possibly overestimated cloud emissivity are sources of uncertainty in HLRADIA LW fluxes in cloudy cases.

This study raised a few development tasks needed for preparation of the HLRADIA for use in the HARMONIEAROME system: 
- The empirical correction term for LWDS fluxes should be optimised to suit both cold/dry and warm/humid conditions under clear and cloudy sky conditions. The constant value used to represent the $\mathrm{CO}_{2}$ concentration should be updated to $400 \mathrm{ppmv}$.

- Experiments to improve the diagnostics of direct/diffuse SW flux formulations in clear-sky and cloudy-sky cases, as well as development and testing of aerosol LW and SW transmission, are required. The impact of aerosols on the observed and simulated SWDS and LWDS needs to be studied by performing experiments using carefully selected clear-sky cases.

- Testing of the simulated SW and LW fluxes and atmospheric heating rates against well-defined reference results for clear-sky and realistic cloud conditions should be continued using a diagnostic single-column modelling framework. Special attention needs to be paid to the analysis of factors relating to cloud microphysical and optical properties. The scheme for HLRADIA LW radiative transfer should probably be improved for complex cloudy conditions where multiple cloud layers of different temperatures are involved. Comparisons of atmospheric profiles of SW fluxes and heating profiles against benchmark results have been left for a further study.

A preliminary example of 3-D HARMONIE-AROME experiments in a convective situation over China indicate that the results are sensitive to the calling frequency and choice of radiation parametrizations. Systematic three-dimensional experiments using the IFSRADIA, HLRADIA and ACRANEB radiation parametrizations are necessary in order to evaluate the impact of the calling frequency and properties of the radiation schemes on weather forecast. Model-observation comparisons using advanced diagnostics are needed to understand the interactions between radiative transfer and clouds and between radiation and the surface in the model and in nature.

Data availability. For the CIRC section, the input data were obtained from a published source as referred to while results and methods are reported in the present paper. Input data for the ten-year comparison is attached as a supplement. For the MarcoPolo example, input and output data of HARMONIE NWP experiments are stored in the ECMWF archives and can be obtained by contacting the authors as there is currently no publicly available method for this data access.

The Supplement related to this article is available online at https://doi.org/10.5194/asr-14-195-2017-supplement.
Author contributions. LR and EG wrote the paper, with input from KPN, PR, BHS and HS. EG ran the CIRC experiments. LR carried out the 10-year evaluation of HLRADIA in HIRLAM. The Marco Polo experiments were prepared by KPN.

Competing interests. The authors declare that they have no conflict of interest.

Special issue statement. This article is part of the special issue "16th EMS Annual Meeting \& 11th European Conference on Applied Climatology (ECAC)". It is a result of the 16th EMS Annual Meeting \& 11th European Conference on Applied Climatology (ECAC), Trieste, Italy, 12-16 September 2016.

Acknowledgements. Our thanks are due to Ján Mašek for providing the NBM reference and support for the CIRC comparison experiments as well as for valuable suggestions which improved this manuscript. We thank Anders Lindfors for information and discussions related to the interpretation of the Jokioinen and Sodankylä radiation observations. The support of the International HIRLAM-C and ALADIN programmes is also acknowledged.

Edited by: Gert-Jan Steeneveld

Reviewed by: two anonymous referees

\section{References}

Anderson, G. P., Clough, S. A., Kneizys, F. X., Chetwynd, J. H., and Shettle, E. P.: AFGL Atmospheric Constituent Profiles (0120 km), Tech. Rep. AFGL-TR-86-0110, Air Force Geophysics Lab Hanscom AFB, MA, USA, 1986.

ARM: ARM Climate Research Facility, available at: https://www. arm.gov/ (last access: 23 November 2016), 2016.

Arola, A., Lindfors, A., Natunen, A., and Lehtinen, K. E. J.: A case study on biomass burning aerosols: effects on aerosol optical properties and surface radiation levels, Atmos. Chem. Phys., 7, 4257-4266, https://doi.org/10.5194/acp-7-4257-2007, 2007.

Baklanov, A., Korsholm, U. S., Nuterman, R., Mahura, A., Nielsen, K. P., Sass, B. H., Rasmussen, A., Zakey, A., Kaas, E., Kurganskiy, A., Sørensen, B., and Gonz'lez-Aparicio, I.: The EnviroHIRLAM online integrated meteorology-chemistry modelling system: strategy, methodology, developments, and applications, Geosci. Model Dev. Discuss., https://doi.org/10.5194/gmd-2016319, in review, 2017.

Bengtsson, L., Andrae, U., Aspelien, T., Batrak, Y., Calvo, J., de Rooy, W., Gleeson, E., Hansen-Sass, B., Homleid, M., Hortal, M., Ivarsson, K., Lenderink, G., Niemelä, S., Pagh Nielsen, K., Onvlee, J., Rontu, L., Samuelsson, P., Santos Muñoz, D., Subias, A., Tijm, S., Toll, V., Yang, X., and Ødegaard Køltzow, M.: The HARMONIE-AROME model configuration in the ALADINHIRLAM NWP system, Mon. Weather Rev., 145, 1919-1935, https://doi.org/10.1175/MWR-D-16-0417.1, 2017.

Clough, S. A., Shephard, M. W., Mlawer, E. J., Delamere, J. S., Iacono, M. J., Cady-Pereira, K., Boukabara, S., and Brown, P. D.: 
Atmospheric radiative transfer modeling: a summary of the AER codes, J. Quant. Spectrosc. Ra., 91, 233-244, 2005.

ECMWF: IFS documentation, Chapter 2, available at: http://www.ecmwf.int/sites/default/files/elibrary/2015/

9211-part-iv-physical-processes.pdf (last access: 1 February 2017), 2015.

Eerola, K.: Twenty-one years of verification from the HIRLAM NWP system, Weather Forecast., 28, 270-285, https://doi.org/10.1175/WAF-D-12-00068.1, 2013.

Faroux, S., Kaptué Tchuenté, A. T., Roujean, J.-L., Masson, V., Martin, E., and Le Moigne, P.: ECOCLIMAP-II/Europe: a twofold database of ecosystems and surface parameters at $1 \mathrm{~km}$ resolution based on satellite information for use in land surface, meteorological and climate models, Geosci. Model Dev., 6, 563582, https://doi.org/10.5194/gmd-6-563-2013, 2013.

Geleyn, J. F., Mašek, J., Brožková, R., Kuma, P., Degrauwe, D., Hello, G., and Pristov, N.: Single interval longwave radiation scheme based on the net exchanged rate decomposition with bracketing, Q. J. Roy. Meteor. Soc., 143, 1313-1335, https://doi.org/10.1002/qj.3006, 2017.

Gleeson, E., Nielsen, K. P., Toll, V., and Rontu, L.: Shortwave Radiation Experiments in HARMONIE. Tests of the cloud inhomogeneity factor and a new cloud liquid optical property scheme compared to observations, ALADIN-HIRLAM Newsletter 5, 92-106, available at: http://www.cnrm.meteo.fr/aladin/IMG/pdf/ nl5.pdf (last access: 1 February 2017), 2015.

Gleeson, E., Toll, V., Nielsen, K. P., Rontu, L., and Mašek, J.: Effects of aerosols on clear-sky solar radiation in the ALADINHIRLAM NWP system, Atmos. Chem. Phys., 16, 5933-5948, https://doi.org/10.5194/acp-16-5933-2016, 2016.

Hu, Y.X. and Stamnes, K.: An Accurate Parameterization of the Radiative Properties of Water Clouds Suitable for Use in Climate Models. J. Climate, 6, 728-742, https://doi.org/10.1175/15200442(1993)006<0728:AAPOTR>2.0.CO;2, 1993.

Kangas, M., Rontu, L., Fortelius, C., Aurela, M., and Poikonen, A.: Weather model verification using Sodankylä mast measurements, Geosci. Instrum. Method. Data Syst., 5, 75-84, https://doi.org/10.5194/gi-5-75-2016, 2016.

Koepke, P., Hess, M., Schult, I., and Shettle, E. P.: Global Aerosol Data Set, Report No. 243, Max-Planck-Institut für Meteorologie, Hamburg, Germany, ISSN 0937-1060, 1997.

Lindfors, A., Kaurola, J., Arola, A., Koskela, T., Lakkala, K., Josefsson, W., Olseth, J. A., and Johnsen, B.: A method for reconstruction of past UV radiation based on radiative transfer modeling: Applied to four stations in northern Europe, J. Geophys. Res., 112, D23201, https://doi.org/10.1029/2007JD008454, 2007.

Manners, J., Thelen, J.-C., Petch, J., Hill, P., and Edwards, J. M.: Two fast radiative transfer methods to improve the temporal sampling of clouds in numerical weather prediction and climate models, Q. J. Roy. Meteor. Soc., 135, 457-468, https://doi.org/10.1002/qj.385, 2009.

Martin, G. M., Johnson, D. W., and Spice, A.: The measurement and parameterization of effective radius of droplets in warm stratocumulus clouds, J. Atmos. Sci., 51, 1823-1842, https://doi.org/10.1175/15200469(1994)051<1823:TMAPOE>2.0.CO;2, 1994.

Mašek, J., Geleyn, J. F., Brožková, R., Giot, O., Achom, H. O., and Kuma, P.: Single interval shortwave radiation scheme with parameterized optical saturation and spectral overlaps, Q. J. Roy.
Meteor. Soc., 142, 304-326, https://doi.org/10.1002/qj.2653, 2016.

Masson, V., Le Moigne, P., Martin, E., Faroux, S., Alias, A., Alkama, R., Belamari, S., Barbu, A., Boone, A., Bouyssel, F., Brousseau, P., Brun, E., Calvet, J.-C., Carrer, D., Decharme, B., Delire, C., Donier, S., Essaouini, K., Gibelin, A.-L., Giordani, H., Habets, F., Jidane, M., Kerdraon, G., Kourzeneva, E., Lafaysse, M., Lafont, S., Lebeaupin Brossier, C., Lemonsu, A., Mahfouf, J.-F., Marguinaud, P., Mokhtari, M., Morin, S., Pigeon, G., Salgado, R., Seity, Y., Taillefer, F., Tanguy, G., Tulet, P., Vincendon, B., Vionnet, V., and Voldoire, A.: The SURFEXv7.2 land and ocean surface platform for coupled or offline simulation of earth surface variables and fluxes, Geosci. Model Dev., 6, 929-960, https://doi.org/10.5194/gmd-6-929-2013, 2013.

Mayer, B. and Kylling, A.: Technical note: The libRadtran software package for radiative transfer calculations - description and examples of use, Atmos. Chem. Phys., 5, 1855-1877, https://doi.org/10.5194/acp-5-1855-2005, 2005.

Nielsen, K. P., Gleeson, E., and Rontu, L.: Radiation sensitivity tests of the HARMONIE 37h1 NWP model, Geosci. Model Dev., 7, 1433-1449, https://doi.org/10.5194/gmd-7-1433-2014, 2014.

Nielsen, K. P., Georgoulias, A. K., Kourtidis, K., and Stathopoulos, S.: Relationship between air pollution and meteorology, Deliverable D 5.4 from the EU FP7 project: Monitoring and Assessment of Regional air quality in China using space Observations (MarcoPolo), https://www.researchgate.net/profile/Kristian_Nielsen/project, last access: 3 July 2017.

Ou, S.-C. and Liu, K.-N.: Ice microphysics and climatic temperature feedback, Atmos. Res., 35, 127-138, 1995.

Oreopoulos, L., Mlawer, E., Delamere, J., Shippert, T., Cole, J., Fomin, B., Iacono, M., Jin, Z., Li, J., Manners, J., Räisänen, P., Rose, F., Zhang, Y., Wilson, M. J., and Rossow, W. B.: The continual intercomparison of radiation codes: Results from phase I., J. Geophys. Res., 117, D06118, https://doi.org/10.1029/2011JD016821, 2012.

Paltridge, G. W. and Platt, C. M. R.: Radiative processes in meteorology and climatology. Developments in atmospheric science, Elsevier Scientific Pub. Co., Amsterdam, 1976.

Pincus, R. and Stevens, B.: Paths to accuracy for radiation parameterizations in atmospheric models, J. Adv. Model. Earth Syst., 5, 225-233, https://doi.org/10.1002/jame.20027, 2013.

Riihelä, A., Carlund, T., Trentman, J., Müller, R., and Lindfors, A.: Validation of CM SAF Surface Solar Radiation Datasets over Finland and Sweden, Remote Sens., 7, 6663-6682, https://doi.org/10.3390/rs70606663, 2015.

Rontu, L., Wastl, C., and Niemelä, S.: Influence of the details of topography on weather forecast - evaluation of HARMONIE experiments in the Sochi Olympics domain over the Caucasian mountains, Front. Earth Sci., 4, 13 pp., https://doi.org/10.3389/feart.2016.00013, 2016a.

Rontu, L., Gleeson, E., Nielsen, K. P., Toll, V., and Mašek, J.: HARMONIE radiation studies 2011-2016, ALADIN-HIRLAM Newsletter No. 7, 92-106, available at: http://www.cnrm.meteo. fr/aladin/IMG/pdf/nl7.pdf (last access: 1 February 2017), $2016 \mathrm{~b}$.

Rummukainen, M., Räisänen, J., Bringfelt, B., Ullerstig, A., Omstedt, A., Willén, U., Hansson, U., and Jones, C.: A regional climate model for northern Europe: model description and results from the downscaling of two GCM control simulations, Clim. 
Dynam., 17, 339-359, https://doi.org/10.1007/s003820000109, 2001.

Räisänen, P., Rummukainen, M., and Räisänen, J.: Modification of the HIRLAM radiation scheme for use at the Rossby Centre Regional Atmospheric Climate Model. Department of Meteorology, University of Helsinki, Report No. 49, 71 pp., 2000a.

Räisänen, P., Rummukainen, M., and Räisänen, J.: Modification of the HIRLAM radiation scheme for use at the Rossby Centre, HIRLAM Newsletter, 36, 48-54, available at: http://hirlam.org (last access: 1 February 2017), 2000b.

Sass, B. H., Rontu, L., and Räisänen, P.: HIRLAM-2 Radiation scheme: Documentation and tests, HIRLAM Technical report, 16, available at: http://hirlam.org (last access: 1 February 2017), 1994.

Savijärvi, H.: Fast Radiation Parameterization Schemes for Mesoscale and Short-Range Forecast Models, J. Appl. Meteorol., 29, 437-447, 1990.

Savijärvi, H., Arola, A., and Räisänen, P.: Short-wave optical properties of precipitating water clouds, Q. J. Roy. Meteor. Soc., 123, 883-899, https://doi.org/10.1002/qj.49712354005, 1997.

Schomburg, A., Venema, V., Ament, F., and Simmer, C.: Application of an adaptive radiative transfer scheme in a mesoscale numerical weather prediction model, Q. J. Roy. Meteor. Soc., 138, 91-102, https://doi.org/10.1002/qj.890, 2012.

Seity, Y., Brousseu, P., Malardel, S., Hello, G., Benard, P., Bouttier, F., Lac, C., and Masson, V.: The AROME-France convectivescale operational model, Mon. Weather Rev., 139, 976-991, https://doi.org/10.1175/2010MWR3425.1, 2011.

Senkova, A. V., Rontu, L., and Savijärvi, H.: Parametrization of orographic effects on surface radiation in HIRLAM, Tellus A, 59, 279-291, https://doi.org/10.1111/j.1600-0870.2007.00235.x, 2007.

Stamnes, K., Tsay, S.-C., Wiscombe, W., and Jayaweera, K.: Numerically stable algorithm for discrete-ordinate-method radiative transfer in multiple scattering and emitting layered media, Appl. Optics, 27, 2502-2509, 1988.

Stamnes, K., Tsay, S.-C., and Laszlo, I.: DISORT, a GeneralPurpose Fortran Program for Discrete-Ordinate-Method Radiative Transfer in Scattering and Emitting Layered Media: Documentation and Methodology, Tech. rep., Stevens Insitute of Technology, Hoboken, NJ, USA, 2000.
Sun, Z.: Reply to comments by Greg M. McFarquhar on "Parametrization of effective sizes of cirrus-cloud particles and its verification against observations", Q. J. Roy. Meteor. Soc., 127, 267-271, 2001.

Sun, Z. and Rikus, L.: Parametrization of effective sizes of cirruscloud particles and its verification against observations, Q. J. Roy. Meteor. Soc., 125, 3037-3055, 1999.

Thomas, G. E. and Stamnes, K.: Radiative Transfer in the Atmosphere and Ocean, Cambridge University Press, New York, NY, USA, 2002.

Tiedtke, M.: An Extension of Cloud-Radiation Parameterization in the ECMWF Model: The Representation of Subgrid-Scale Variations of Optical Depth, Mon. Weather Rev., 124, 745-750, https://doi.org/10.1175/15200493(1996)124<0745:AEOCRP>2.0.CO;2, 1996.

Toll, V., Gleeson, E., Nielsen, K. P., Mannik, A., Mašek, J., Rontu, L., and Post, P.: Impacts of the direct radiative effect of aerosols in numerical weather prediction over Europe using the ALADIN-HIRLAM NWP system, Atmos. Res., 163-173, https://doi.org/10.1016/j.atmosres.2016.01.003, 2016.

Unden, P., Rontu, L., Arvinen, H., Lynch, P., Calvo, J., Cats, G., Cuxart, J., Eerola, K., Fortelius, C., Garcia-Moya, J. A., Jones, C., Lenderlink, G., McDonald, A., McGrath, R., Navascues, B., Woetman Nielsen, N., Odegaard, V., Rodriguez, E., Rummukainen, M., Room, R., Sattler, K., Hansen Sass, B., Savijärvi, H., Wichers Schreur, B., Sigg, R., The, H., and Tijm, A.: The HIRLAM version 5.0 model. HIRLAM documentation manual (HIRLAM Scientific Documentation), available at: http://hirlam.org (last access: 1 February 2017), 2002.

Venema, V., Schomburg, A., Ament, F., and Simmer, C.: Two adaptive radiative transfer schemes for numerical weather prediction models, Atmos. Chem. Phys., 7, 5659-5674, https://doi.org/10.5194/acp-7-5659-2007, 2007.

Wastl, C., Mary, A., Seity, Y., Rontu, L., and Wittmann, C.: Parameterization of orographic effects on surface radiation in AROMESURFEX, ALADIN-HIRLAM Newsletter No. 5, 81-82, available at: http://www.cnrm.meteo.fr/aladin/IMG/pdf/nl5.pdf (last access: 1 February 2017), 2015.

Wyser, K., Rontu, L., and Savijärvi, H.: Introducing the Effective Radius into a Fast Radiation Scheme of a Mesoscale Model, Contr. Atmos. Phys., 72, 205-218, 1999. 